\title{
Lot-Size One Production
}

\author{
Udo Kannengiesser, Richard Heininger, Lubomir Billy, \\ Pavol Terpak, Matthias Neubauer, Christian Stary, Dennis Majoe, \\ Alexandra Totter and David Bonaldi
}

\begin{abstract}
This case reports on an SME offering the production of atypical, unique and special-purpose machinery, equipment and technological complex units useful particularly in the automotive and electronic industries. The initial situation reveals challenges like the estimation of production times for one-time prototypes, lack of communication between shop floor workers and technologists, lack of information on upcoming production tasks for workplaces, low involvement of workers in decision processes, and lack of information on current state of production. The proposed subject-oriented solution targets to increase the worker autonomy, the worker involvement and information transparency as well as integration across all organizational control layers. In this respect, subject-orientation is applied to integrate real-time information from the shop floor (e.g. location information of parts, power consumption of machines) and business processes (e.g. customer order). A novel S-BPM modelling approach has been developed in the course of organizational design that seeks to model subjects as fine-grained behaviours of actors rather than functional roles. The
\end{abstract}

U. Kannengiesser $(\square) \cdot$ R. Heininger

Metsonic GmbH, Pfaffenhofen, Germany

e-mail: udo.kannengiesser@gmail.com

L. Billy $\cdot$ P. Terpak

Centire, Bratislava, Slovakia

M. Neubauer · C. Stary

Department of Business Information Systems - Communications Engineering, Johannes

Kepler University Linz, Linz, Austria

D. Majoe

MA Systems and Control Limited, Southampton, UK

A. Totter · D. Bonaldi

ByElement, Schindellegi, Switzerland

(C) The Author(s) 2017

M. Neubauer and C. Stary (eds.), S-BPM in the Production Industry,

DOI 10.1007/978-3-319-48466-2_4 
revealed behaviours may be assigned to actors (i.e. humans, machines) depending on their capabilities and skills. This allows for dynamic allocation of tasks to humans and machines, process execution support based on skill levels, reflecting performed behaviours of actors and (de-)constructing organizational behaviours. The evaluation is composed of formative and summative elements. The formative evaluation reports on findings based on developer workshops, focus groups and user tests that were conducted in parallel to the design and implementation to ensure a user-centred approach. The summative evaluation reports on findings related to the outcome of the case implementations at the SME.

\subsection{Elicitation and Analysis of the Initial Situation}

The case described in this chapter has occurred in a manufacturing SME called "Company A" in Slovakia. This company was established in 1990 and is operating in the field of precise mechanical engineering, ranging from mechanical nodes, operational units and systems to special single-purpose machines and technological complexes, including control systems. Until recently it also performed the development, construction and project planning of such devices. In addition to its extensive modern technological equipment including CNC (Computerized Numerical Control) machines, measuring devices and other tools, the company relies on a broad team of engineers and shop floor workers.

Company A produces atypical, unique and special-purpose machinery, equipment and technological complexes (including electronic control systems). Its regular customers are from the automotive and electrical industries. The company production includes the manufacturing of high-precision components by chip machining as well as using unconventional methods of IT 4 class metalworking, encompassing general 3- to 5-D surfaces.

The case analysis and definition involved a range of activities

- Factory visits of project partners

- Face-to-face workshop with project partners (brainstorming sessions, interviews with management and employees)

- Definition of key terminologies ensuring common understanding of partners

- Remote conference calls to further specify the use case

- Discussions and interviews with workers and engineers

- Definition of goals, objectives and criteria by each partner. 


\subsubsection{Management Workshop}

The definition of possible focus areas of the case started with an initial workshop at Company A. One member of Company A's management team and members of the several SO-PC-Pro partners (Regional IT consultant, HCI consultant, hardware developer, S-BPM system provider, JKU researcher) joined this workshop. The goal was to

- Identify and analyze areas of improvement or production problems

- Create ideas to address possible solutions

- Depict possible use case scenarios, and

- Prioritize the results at the end of the workshop in order to focus work and align work packages

The workshop's participants started with a brainstorming session to identify possible areas of improvement. The discussion among the partners led to the definition of the following six use case candidates:

\section{Decentralized coordination of workers in the production process}

In the initial situation, workers operate on the shop floor and do not usually gain insight into production planning. This leads to centralized coordination of tasks by the management, which on the other hand may lead to inefficiencies and unnecessary idle times. Decentralized coordination of work tasks and involvement of workers in operative planning of tasks at the shop floor is envisioned as solution to this problem.

\section{Task assignment by workers}

Workers gain autonomy in choosing their work task at the shop floor. This could increase self-efficacy and is believed to shorten idle times of machines and workers.

\section{Proactive maintenance of the machines}

If machines on the shop floor need to be maintained, these machines cannot be used for production. Therefore, a proactive maintenance of the machines during idle times would increase productivity - machines would be out of order to a lesser extent.

\section{Material tracking}

Another issue at Company A is the predictability of delivery dates of finished work pieces. Due to the prototype-based production setting nearly every piece has a different production plan. Therefore, it is not easy to track material and unfinished work pieces on their way through the shop floor, because pieces have different 
routes. Location sensing could ensure traceability and tracking capabilities for produced work pieces.

5. Machining task complexity versus worker skill level prediction and management complexity of the new parts

The production planning of new work pieces always takes place in the technological preparation office. It is primarily based on the experience of technologists. The introduction of indicators for task complexity and required worker skill level could help technologists to estimate needed work time. As a result, a better estimation regarding the needed production time for new work pieces could be calculated.

\section{Making use of the idle time}

When workers are waiting for a machining task, they usually have to wait until this task is finished. Workers could prepare their next steps during this idle time (e.g. get tools for the next operation), if they could get insight into the production plan. On the other hand, the machining task has to be observed by sensors to ensure that workers get notified in case a manual intervention is necessary.

The identified use case candidates were then evaluated according to five dimensions as the next step. These dimensions were derived with respect to the overall goals and the specified work packages of the SO-PC-Pro project. The five dimensions are

- Aspects regarding process automation

- Human-centeredness aspects

- Impact on Company A's management and effectiveness of production

- Potential usage of S-BPM for supporting communication and execution

- Degree of involvement of the project partners.

The first use case candidate was prioritized highest after the discussion along these dimensions. It was additionally possible to extend this use case with elements of the other candidates. However, proactive maintenance of machines was dropped after this discussion.

\subsubsection{Interviewing the Employees}

The next step in identifying areas of improvement was to conduct semi-structured interviews with various employees of the company. The result of the initial workshop was taken into account for structuring the interview, however, employees were able to address their problems without reservations. The in-depth interviews revealed the following four use case candidates from the employees' perspective. 


\section{Monitoring tools on the shop floor to decrease production postponing}

Employees reported during the interviews that tools cannot be found on the shop floor occasionally. The finding process involves production manager as well as employees. Therefore, it would help workers to track the location of tools, and it would increase productivity as it decreases preparation time.

\section{Communication improvement between workers on the shop floor, technologists and production management}

Shop floor workers commented on unrealistic and improvable time estimations of technologists. They mentioned fostering communication of all involved parties in the production process as significant potential for improvement.

\section{Proactive machine maintenance}

The periodic maintenance of machines can be postponed by shop floor workers. Thus, machines are not maintained in time, rather too late, namely in the event of an error. Proactive maintenance could help to reduce machine breakdowns.

\section{Cooperation on production time estimation}

Shop floor workers want to participate in estimating production time to avoid unnecessary time pressure, because time estimations were perceived rather optimistic at that time. This issue was addressed in the interviews in the context of improving communication among employees.

The following paragraphs highlight selected statements from the conducted interviews. The citations have been translated and edited for readability

It's a constant struggle to satisfy our customers, to ensure quality, and also quantity. It is about finding a balance between these dimensions. Hopefully this project helps to make things easier and provides an improved management system taking a different perspective on the production operation of the company. The current system is outdated and not the right one. New IT systems are more flexible, and help the management of the company to operate more efficiently and flexibly. (An employee on the everyday work at Company A)

The human represents a major influencing factor, I think that simply providing a new system is not a good solution...Work procedures should be more standardized. However, this is challenging due to the fact that our company offers single-piece production and more or less prototyping. We do not do serial production, and repeatability is rather low... I would estimate $20 \%$ of the orders. The introduction of a new system for reducing the waste of time in production will be challenging. The new system should provide information on the current distribution of tools among dedicated locations (e.g. workplaces or the tool warehouse). Workers often require a tool which is currently used by someone else or even not available on the shop floor at all. In the latter case, the work task needs to be interrupted and the shop floor leader needs to procure the necessary tool. Such cases lead to my opinion to severe delays and waste of time. (An employee on the possibility of introducing a new system solving the waste of time in production) 
Every worker receives the work to be done on the shelf related to his workplace in terms of the blueprint and the material/part required to perform a given operation. A worker is supposed to deal with orders on the shelf according to the deadlines on the blueprint. Of course there are situations, when the management tells a worker: This order is now more important, work on this. However, people are diverse - sometimes they choose what they want, and change planned sequences. That is how people actually perform work today. (An employee on the lack of autonomy regarding task selection)

Work became much harder, in former times it was easier. We have had small serial production and also single-piece production. However, in both cases the estimation of the actual production time is hard to estimate. Someone (a technologist or production manager) estimates a time for a certain manufacturing operation, and even that time is five times smaller than the actual time, workers need to deal with it. It dishonours our work. I have no clue why they always decrease the time in order to increase our work speed, I really don't know. (An employee on the difficulty of accurate time estimations)

The communication between involved people - technologist, shop floor leader, worker - is important. Typically, workers are the last one in the design of the manufacturing operations for a certain order. However, workers know how to perform manufacturing operations best... Therefore, direct communication between the technologists and shop floor workers is important.

Technologists should definitely visit the shop floor more frequently. There is a lack in communication with respect to the times for manufacturing operations technologist indicate on the blueprints. A technologist should be more interested, he should inform about production opportunities. We (technologist, worker) should communicate more, since more heads are better than one.

(Two employees on the importance of communication between different departments)

The current tool tracking works as follows. There is a database storing the tools and tasks assigned to a workplace. This database is manually updated by the shop floor leader when someone e.g. finishes a task, or takes a tool from the tool warehouse. However, sometimes the data in the database are not updated, or the tool is left at a workplace even though the database is updated. Then, the shop floor leader or the worker need to search the tool and valuable time is wasted. (An employee on the issue of misplaced tools)

Machine maintenance has not been working very well lately. Only when a machine breaks down, an error is handled. Regarding the regular maintenance, each machine defines maintenance intervals. My machine displays a required maintenance. However, one may easily reset the maintenance interval and proceed working without any maintenance. This results in the fact that workers ignore maintenance until the machine breaks down. (An employee on the machines maintenance)

\subsubsection{Analysis and Goal Definition}

Based on joint discussions of the project team, the list of problems at Company A has been defined. On this basis, the problems have been addressed by different use cases. The common agreement singled out the first use case candidate of the initial workshop as the most appropriate and most important use case. Its importance was confirmed by the in-depth interviews with the shop floor workers. 
The results of the workshop and the interviews were summarized subsequently. When doing so, the following hindering factors have been identified:

- The one-time production of prototypes (batch size =1) challenges time estimation

- Lost material/parts and tools

- Lack of communication between workers on the shop floor, technologists and production management (e.g. on-time estimations, possible process optimizations)

- Workers lack of information considering upcoming manufacturing tasks which could be beneficial to prepare in advance and make use of the idle time

- Production manager is a single point of failure. He needs to distribute parts across different workplaces manually and, therefore, lacks time for planning and monitoring

- Machined parts are often forgotten on the shelf, which affect the production fluency. There is also missing information about when a task started or ended (this information is inserted in the internal production software by the production manager after certain period of time)

- The current production control system cannot measure the time taken for each manufacturing step at a workstation. The system is not capable of automatically monitoring the current production status of a given part. It depends on manual data input by the production manager. Furthermore, it cannot trace the location and therefore provide tracking information in case parts are lost

- Prioritizing of task/orders/production steps is not documented in the system and easily accessible

- There is a lack of worker-to-worker and worker-to-management communication. This often causes interruption of production fluency by, e.g. forgetting to machine a part or to deliver a machined part to another workplace. Communication is then triggered only in case of a problem

The goals and objectives considering this use case have been defined collaboratively with the project partners. In a further step, each project partner contributing to this case defined goals and objectives relevant from its point of view. The following consolidated list comprises goals and objectives which are addressed in this use case (also see Table 4.1). It is the result of an iterative process aiming for aligning the partners' viewpoints.

Optimized production processes through automation support are the umbrella goal for the three main goals identified for the case implementation. The first main goal is the decentralization of task assignments. This goal is composed of the following two objectives:

- Support employees' work-autonomy by self-determined task selection in alignment with the overall production plan

- Involve workers in the decentralized distribution of work pieces in line with the production plan. 
The decentralized assignment of tasks follows the idea to decrease operational effort of the production manager and increase the autonomy of the worker. To do so, workers should be enabled to select manufacturing tasks individually on the basis of the current production plan. Support information could be a prioritized list of upcoming manufacturing tasks as well as already estimated manufacturing times. This information would also allow workers to plan ahead within the context of their workplace and for example, make use of the idle time by preparing for upcoming work tasks. Beyond that, the first goal comprises the involvement of workers in the distribution of parts, e.g. workers bring proactive parts to the next station within the idle time or they get parts to be manufactured from other workers.

Facilitation of real-time production state tracking is the second main goal in this use case. This goal will be achieved by reaching two objectives. These objectives mainly address the issue regarding lost parts and tools.

The increase of the transparency of material/part location by real-time tracking on the shop floor focuses on providing information about the actual production state. Having this real-time information allows on the one hand for a better overview of the production from the production manager's view point (e.g. production planning, estimation) and on the other hand gives the workers information about upcoming tasks, and thus, improves task preparation (e.g. preparation of programs).

The reduction of time needed to search for lost tools and parts/materials does not focus on providing status, but rather on actual location information. It could reduce the time needed to search for certain part/tools. Moreover, the availability of this data supports the workers in the decentralized distribution of work pieces as described above.

The third main goal covers the improvement of mutual information exchange between subjects. Subjects are actors within processes and can be represented by either humans or machines involved in the manufacturing process. This goal is detailed by the following four objectives:

- Improving human 2 human communication

- Improving human 2 machine communication

- Improving machine 2 human communication

- Improving machine 2 machine communication

The improvement of human 2 human communication comprises, e.g. the improvement of communication between worker and technical planner on time estimations in terms of the alignment and negotiation of estimated and actual manufacturing times. The improvement of human 2 machine communication addresses an easy and non-obstructive support for workers to capture information on ongoing manufacturing tasks. This also relates to the second goal in terms of capturing production states in real time. The improvement of machine 2 human communication focuses on providing workers with comprehensive, relevant contextual information such as upcoming tasks and the ongoing production status. The forth objective addresses seamless information exchange between production machines and the production planning systems, e.g. integration of production 
Table 4.1 Consolidated goals and objectives

\begin{tabular}{|c|c|c|}
\hline Overall goal & Goal & Objective \\
\hline \multirow[t]{8}{*}{$\begin{array}{l}\text { Optimized production } \\
\text { processes through } \\
\text { automation support }\end{array}$} & \multirow[t]{2}{*}{$\begin{array}{l}\text { Decentralization of task } \\
\text { assignment }\end{array}$} & $\begin{array}{l}\text { Support employees work-autonomy by } \\
\text { self-determined task selection in alignment } \\
\text { with overall production plan }\end{array}$ \\
\hline & & $\begin{array}{l}\text { Involve workers in the decentralized } \\
\text { distribution of work pieces in line with the } \\
\text { production plan }\end{array}$ \\
\hline & \multirow[t]{2}{*}{$\begin{array}{l}\text { Facilitation of real-time } \\
\text { production state tracking }\end{array}$} & $\begin{array}{l}\text { Increase transparency of material/part } \\
\text { location by real-time tracking on the shop } \\
\text { floor }\end{array}$ \\
\hline & & $\begin{array}{l}\text { Reduction of time needed to search for lost } \\
\text { tools and parts/materials }\end{array}$ \\
\hline & \multirow[t]{4}{*}{$\begin{array}{l}\text { Improvement of mutual } \\
\text { information exchange } \\
\text { between subjects }\end{array}$} & $\begin{array}{l}\text { Improve } \mathrm{H} 2 \mathrm{H} \text { communication (e.g. } \\
\text { communication between worker and } \\
\text { technical planner on time estimations) }\end{array}$ \\
\hline & & $\begin{array}{l}\text { Improve } \mathrm{H} 2 \mathrm{M} \text { communication (e.g. easy } \\
\text { and non-obstructive support for workers to } \\
\text { capture information on ongoing } \\
\text { manufacturing tasks) }\end{array}$ \\
\hline & & $\begin{array}{l}\text { Improve M2H communication (e.g. } \\
\text { comprehensive information of workers on } \\
\text { upcoming tasks and ongoing production } \\
\text { status, relevant contextual information) }\end{array}$ \\
\hline & & $\begin{array}{l}\text { Improve M2M communication (integration } \\
\text { of production control and planning system } \\
\text { with information provided by machines } \\
\text { about current state) }\end{array}$ \\
\hline
\end{tabular}

control and planning system with information provided by machines about current state. For each objective, measurement criteria and methods were defined. Generally, the measurement of objectives comprised qualitative as well as quantitative data.

Overall, the current situation, goals and objectives, the scope and an initial solution idea were defined within the initial use case definition activities. Furthermore, the implementation strategy, testing and evaluation as well as potential risks related to the uses case were defined. Based upon the initial use case definition, additional workshops have been conducted to elicit and narrow down organizational, functional and technical requirements. These requirements are described in terms of S-BPM processes and user stories in the subsequent sections.

\subsubsection{Defining Requirements}

\subsubsection{Organizational Requirements}

To improve the quality of the production process at Company A, it is essential to collect production data in real time, particularly information about the current status of individual production operations and the current location of work pieces. Currently this information is captured manually by the production manager, leading to 


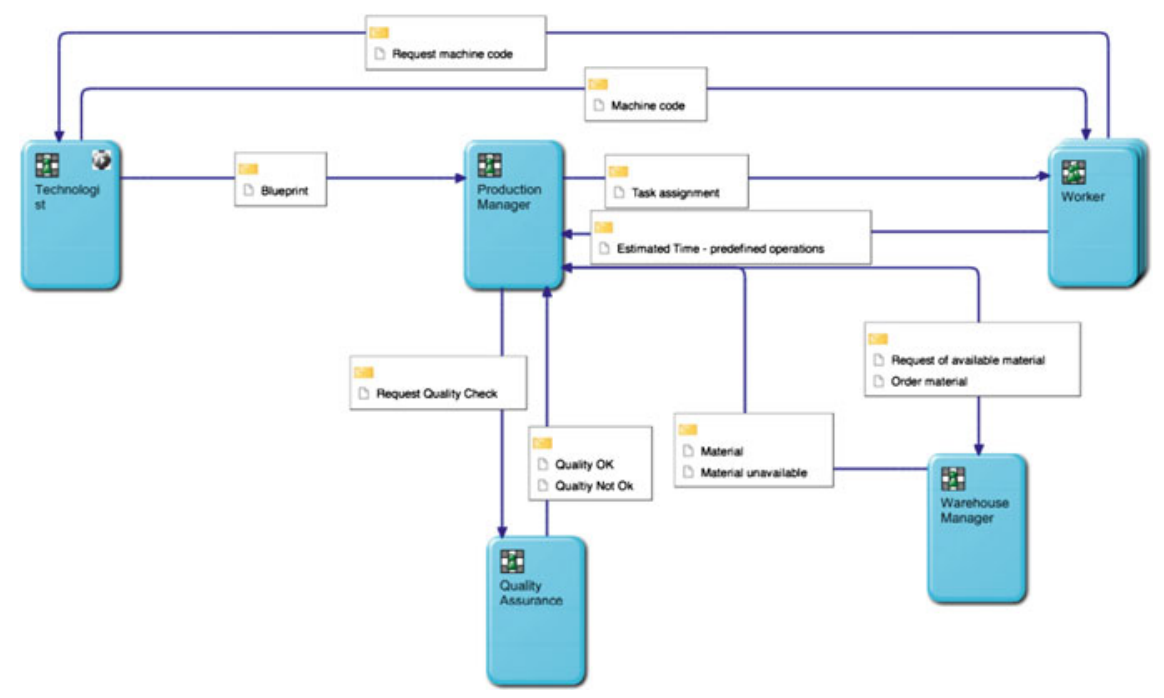

Fig. 4.1 The as-is production process at Company A

time delays and potential errors. The proposed solution will automate the production process, and move the collection of data closer to the production process, by enabling employees and machines to directly access the data in a decentralized way. The solution will be based on an extension of the subject-oriented methodology, consisting of executable models of interacting entities (called the "subjects") representing human operators and machines. Interactions include conveying different types of data, namely, about the status of operations, operators and work pieces/material. They can all be described as messages between subjects that can be interpreted by a subject-oriented workflow execution engine. This allows for the integrated execution, monitoring and analysis of production data, and real-time visibility of production operations. As a result, production orders can be prioritized, providing better guidance for workers when selecting tasks and coordinating their work steps.

Figure 4.1 shows how production is organized at Company A today, using a Subject Interaction Diagram. In the process model, the following subjects (i.e. process-centric roles) are included

- Technologist

- Production Manager

- Worker (shop floor)

- Quality Assurance

- Warehouse Manager 
The initial task of the process is the preparation of a technical specification by the Technologist. After receiving a customer order, the Technologist prepares a technical specification, which comprises the list of required material, the defined technological steps, time estimations for each step, and the required manufacturing precision. These specifications are documented in written form and stored in a production management system, from which a printout, called "blueprint", is produced and given to the Production Manager.

Upon receiving the blueprint, the Production Manager firstly checks with the Warehouse Manager for the availability of required material. If the material is in stock, the Warehouse Manager will provide it directly to the Production Manager; otherwise it will first need to be ordered. The Production Manager assigns to each task defined in the blueprint a particular Worker and Machine, writing this data directly into the production management system. A printout of the production plan is then produced and associated with technical documentation and the corresponding raw material. Subsequently, the Production Manager brings this set of information and material to a small storage shelf near the workplace (i.e. machine and worker) where the first production step is to be executed.

After receiving the task, the Worker checks for the tools required (e.g. milling tool, drilling tool, etc.). If a CNC machine code is needed, the Worker requests it from the Technologist, either directly or via the Production Manager. The Technologist prepares the code and uploads it to a central file server with a unique identifier consisting of order id, machine id and operation id. While waiting for the CNC code, the Worker prepares the workplace and puts the raw material into the machine. Each machine is connected to central file server via Ethernet, so the Worker can find the code, upload it to the machine, validate it and start machining. When the machining operation is finished, the Worker takes out the machined part and puts it on a storage shelf for machined parts. On the production plan, he writes down the time he needed to machine the part. Then, the Production Manager takes the machined part from the shelf and moves it to next workplace. This process is repeated until the last production step is reached.

The last step of the production process is the quality check performed by the Quality Manager. The Quality Manager is responsible for measuring the actual dimensions of the parts produced and checking them against required precision criteria and technical standards. The output is a quality report that includes information on whether the part fulfils desired quality criteria. If the quality has been found insufficient, the Production Manager, in cooperation with the Technologist, devises possible solutions to fix the defects of the part or decides to discard the part and restart the production process.

The current production management system is highly heterogeneous and not sufficient for the needs of Company A. It consists of three independent modules: planning, accounting and warehouse management. It does not support communication via Web services. The database side is not documented well. Consequently, it is almost impossible to ensure correct data exchange between systems, which is crucial for production purposes. 


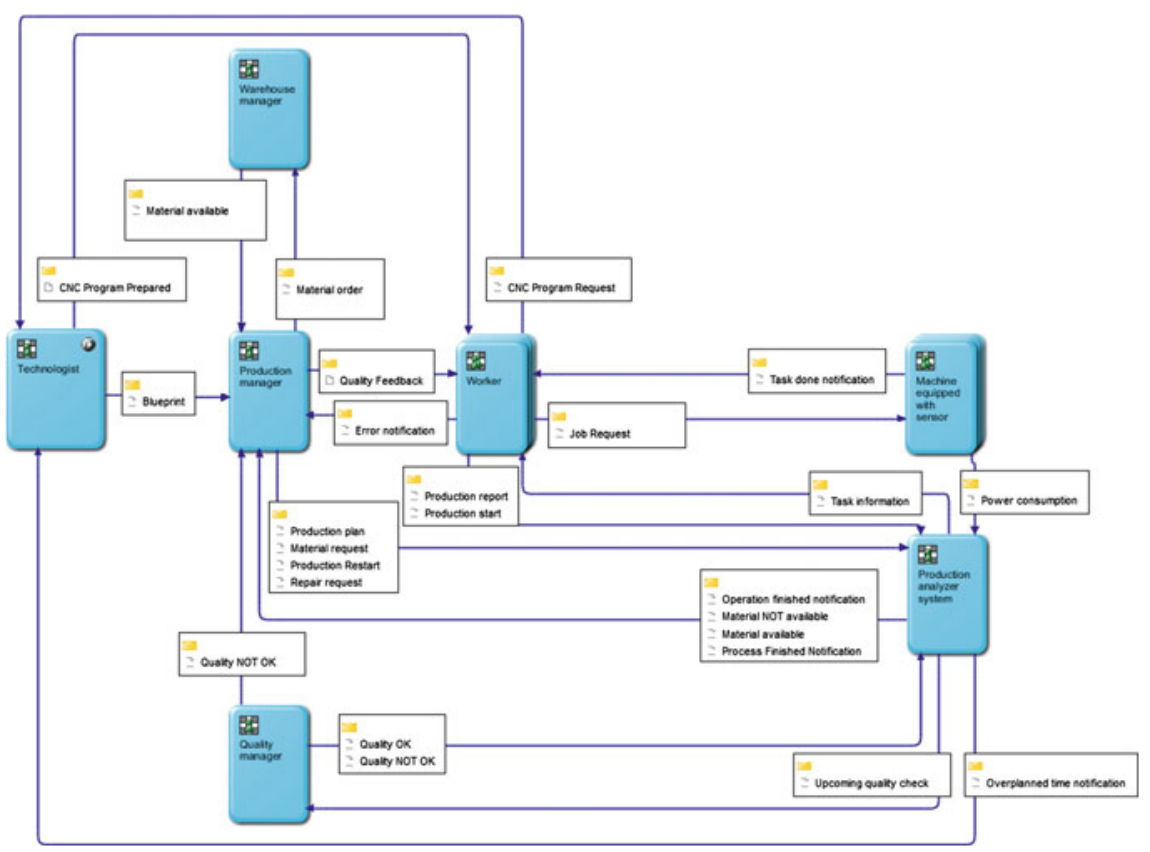

Fig. 4.2 To-be production process at Company A

An initial solution idea for the to-be model of the production process is shown in Fig. 4.2, representing an improved production process with two additional subjects: Machine equipped with sensor and Production Analyzer System.

The production process begins with the Technologist defining the required production information (technical documentation): material, technological steps and estimated time for preparation and production, and required manufacturing precision. Once he has completed this step, he sends this information electronically (via a production planning system) to the Production Manager.

The Production Manager first checks for the availability of the required material with assistance from the Production Analyzer System. If not in stock, the Production Manager sends a request to the Warehouse Manager to order the desired material. Then, he evaluates the technical documentation and assigns each task for particular Workers and Machines using the Production Analyzer System. Each task is associated with a plastic tray with sensor and the material or part to be machined.

After accepting a task, the Worker checks for availability of all required resources (e.g. material, tools) and $\mathrm{CNC}$ codes, and prepares the machine. The moment when he begins to prepare the workplace, the Worker should communicate this state to the Production Analyzer System for time measurement purposes (preparation time). When the Worker clamps the part into the machine, optionally loads the CNC code, he should communicate the state "production start" to the Production Analyzer System. 
Each machine (in the scope of this project) will be equipped with a power consumption sensor attached to machine's power cord. This sensor is crucial to get information whether there is a part being processed on the machine by measuring the amount of power consumption. When power consumption converges to zero, it indicates that the machining operation is almost finished. The system then sends a notification to the Worker.

After taking the processed part out of the machine, the Worker should do a quick quality check. If the Worker finds a defect, he should immediately notify the Production Manager about this situation. The Production Manager then decides whether the part is repairable or restarts production from scratch. The Worker should notify the Production Analyzer System of the time needed for preparation and processing. After confirming the completion of a part, by writing a production report, the Production Analyzer System determines the next operation and notifies the relevant Worker. Then, he takes the processed part with the plastic tray and moves it to next workplace. On the shop floor, the plastic tray equipped with a sensor in combination with wireless access points could provide real-time information where the desired part is located on the shop floor.

The Production Analyzer System monitors the entire production process, gathers signals from sensors via beacon devices as well as location data of parts and tools. The Production Analyzer System also accepts data inputs from the Worker, the Production Manager, the Quality Manager and the Warehouse Manager.

In the very last step of the process, the quality control should take place. The Production Analyzer System notifies the Quality Manager when the quality check is needed. After the Quality Manager has finished the quality check, he produces a quality check report. If the part fails the quality check, the Quality Manager notifies the Production Manager to take further decisions on how to resolve the issue.

\subsubsection{Functional Requirements}

In individual workshops with the management and the workers, user stories have been applied to elicit (functional) requirements. A user story describes a usage scenario using simple natural language. This ensures that all stakeholders, particularly the users of the system to be developed, can understand and contribute to the specification of required system features. Every user story is concerned with exactly one system feature to be implemented, including a description of who will use the feature and for what kind of goal. The following list of user stories contains selected user stories from a management workshop conducted at Company A (Table 4.2).

\subsubsection{Technical Requirements}

In addition to organizational and functional requirements, basic technical requirements have been defined as part of the requirements definition activities. These requirements were classified into requirements related to (1) Company A, (2) the S-BPM processing system and (3) potential sensors to be applied within the use case.

Requirements related to Company A mainly address the availability of devices to access the S-BPM processing system, network configuration, interface 
Table 4.2 User stories

\begin{tabular}{|c|c|c|c|c|c|}
\hline $\begin{array}{l}\text { Story } \\
\text { narrative }\end{array}$ & As a & I want & So that & Priority & $\begin{array}{l}\text { Relation } \\
\text { to goal }\end{array}$ \\
\hline $\begin{array}{l}\text { Increased } \\
\text { task } \\
\text { autonomy }\end{array}$ & Machinist & $\begin{array}{l}\text { to define in which } \\
\text { order to perform "on } \\
\text { the shelf" tasks based } \\
\text { on a list of high and } \\
\text { low prioritized tasks }\end{array}$ & $\begin{array}{l}\text { I can have a level of } \\
\text { freedom and variety } \\
\text { of complexity }\end{array}$ & 2 & 1 \\
\hline $\begin{array}{l}\text { Availability } \\
\text { of CNC } \\
\text { program }\end{array}$ & Machinist & $\begin{array}{l}\text { info on next } 3 \text { tasks } \\
\text { specifically CNC } \\
\text { program }\end{array}$ & $\begin{array}{l}\text { I can upload it or } \\
\text { inform technologist } \\
\text { I don't have it }\end{array}$ & 5 & 3 \\
\hline $\begin{array}{l}\text { Feedback on } \\
\text { quality }\end{array}$ & Machinist & $\begin{array}{l}\text { to have a detailed and } \\
\text { timely feedback on the } \\
\text { quality of a task }\end{array}$ & $\begin{array}{l}\text { I can fully } \\
\text { understand what } \\
\text { was the failing }\end{array}$ & 6 & 3 \\
\hline $\begin{array}{l}\text { Quality } \\
\text { check } \\
\text { planning }\end{array}$ & $\begin{array}{l}\text { Quality } \\
\text { Manager }\end{array}$ & $\begin{array}{l}\text { to know how many } \\
\text { work pieces are in the } \\
\text { last processing stop } \\
\text { before quality check }\end{array}$ & $\begin{array}{l}\text { I can plan my } \\
\text { working time }\end{array}$ & 7 & $1,3,2$ \\
\hline $\begin{array}{l}\text { Planned time } \\
\text { exceeded }\end{array}$ & Technologist & $\begin{array}{l}\text { to get informed if my } \\
\text { planned time is } \\
\text { exceeded by more than } \\
30 \%\end{array}$ & $\begin{array}{l}\text { I can clarify the } \\
\text { reasons and } \\
\text { improve my } \\
\text { estimation of } \\
\text { problems during } \\
\text { production }\end{array}$ & 8 & - \\
\hline $\begin{array}{l}\text { Actual } \\
\text { energy } \\
\text { consumption } \\
\text { for machine }\end{array}$ & $\begin{array}{l}\text { Production } \\
\text { Manager }\end{array}$ & $\begin{array}{l}\text { to see the energy } \\
\text { consumption for a } \\
\text { specific machine at } \\
\text { specific time }\end{array}$ & $\begin{array}{l}\text { I can check if a } \\
\text { machine is operated } \\
\text { by the worker }\end{array}$ & 9 & 3 \\
\hline $\begin{array}{l}\text { Which } \\
\text { workpieces } \\
\text { are at a } \\
\text { specific } \\
\text { machine }\end{array}$ & $\begin{array}{l}\text { Production } \\
\text { Manager }\end{array}$ & $\begin{array}{l}\text { to see the list of orders } \\
\text { at a workplace }\end{array}$ & $\begin{array}{l}\text { I can optimize the } \\
\text { production plan }\end{array}$ & 10 & 2 \\
\hline $\begin{array}{l}\text { Error } \\
\text { notification } \\
\text { by worker }\end{array}$ & $\begin{array}{l}\text { Production } \\
\text { Manager }\end{array}$ & $\begin{array}{l}\text { the worker notifying } \\
\text { me if he makes an } \\
\text { operation error }\end{array}$ & $\begin{array}{l}\text { I can manage the } \\
\text { issue }\end{array}$ & 14 & 3 \\
\hline
\end{tabular}

Note The numbers in the last column ("Relation to Goal") relate to the use case goals specified in Sect. 4.1.3: 1-Decentralization of task assignment; 2-Facilitation of real-time production state tracking; 3-Improvement of mutual information exchange between subjects

definitions to existing production support systems involved in the use case and a server set-up for the S-BPM processing system. Requirements related to the S-BPM processing system Metasonic Suite comprise the operating system and database configuration. Requirements related to the sensor application are on the one hand generic in terms of "not-invasive" (e.g. power metering of a machine) and on the other hand include the compliance with OPC UA (IEC 62541) since a vendor-independent implementation of interfaces between S-BPM processes and sensors has been the target of Metasonic. 


\subsection{Process and Solution Design}

The solution design and development followed a user-centred design approach. Based on the people-centred workplace analysis and requirements specification, first user interface prototypes and S-BPM process specifications were generated by the regional IT consultant and the S-BPM platform provider Metasonic. Subsequently, the results of the initial solution design for the user interfaces are presented.

\subsubsection{Prototyping User Interfaces}

Dedicated user interfaces for workers in the shop floor and the management (production manager, quality manager) have been designed. The user interfaces for workers on the shop floor comprise the following functionalities:

- Provision of upcoming tasks and production information for individual workplaces

- Propose change in task list to optimize workplace-related task sequence (Fig. 4.4)

- Request CNC code (Fig. 4.5)

- Report error (Fig. 4.6)

Figure 4.3 displays the current ordered task list at a certain workplace on the left-hand side. When selecting a certain task, the details appear in the main area. In Fig. 4.3 a "cutting" task related to the order 14285 for Bosch is selected. For the operation the order details, material details, technical operations and the technical documentation may be checked by the worker. Two buttons on top allow to "start production" (green button) or to "propose a change in the task sequence" (grey button). When requesting a change in the proposed task sequence, a worker may reorder the list and provide his rationale for the reordering request before sending it to the production management (cf. Fig. 4.4). After requesting a change in the task sequence, the changed tasks are displayed in grey on the left-hand side (cf. Fig. 4.5). After starting a certain operation (cf. Fig. 4.5), a worker may report an error (red button), request a CNC code, or finish the task without any CNC code request. Reporting error (Fig. 4.6) is supported in the mock-up via a text field for describing the error and a radio group for selecting the type of error. Thus, context-sensitive error reporting is facilitated.

Additionally, interfaces dedicated to the production management have been designed. Inspired by the Kanban approach, the UI designers proposed a Kanban board-like visualization of the current state of production. Thus, the production management may take a look at which tasks are for example currently assigned to "Technological Planning", "Plan Validation", "Work Task Delegation" (cf. Fig. 4.7). One may also filter the distribution, e.g. according to "Only Active Tasks", "Only Inactive Tasks", or "Only my Tasks". 


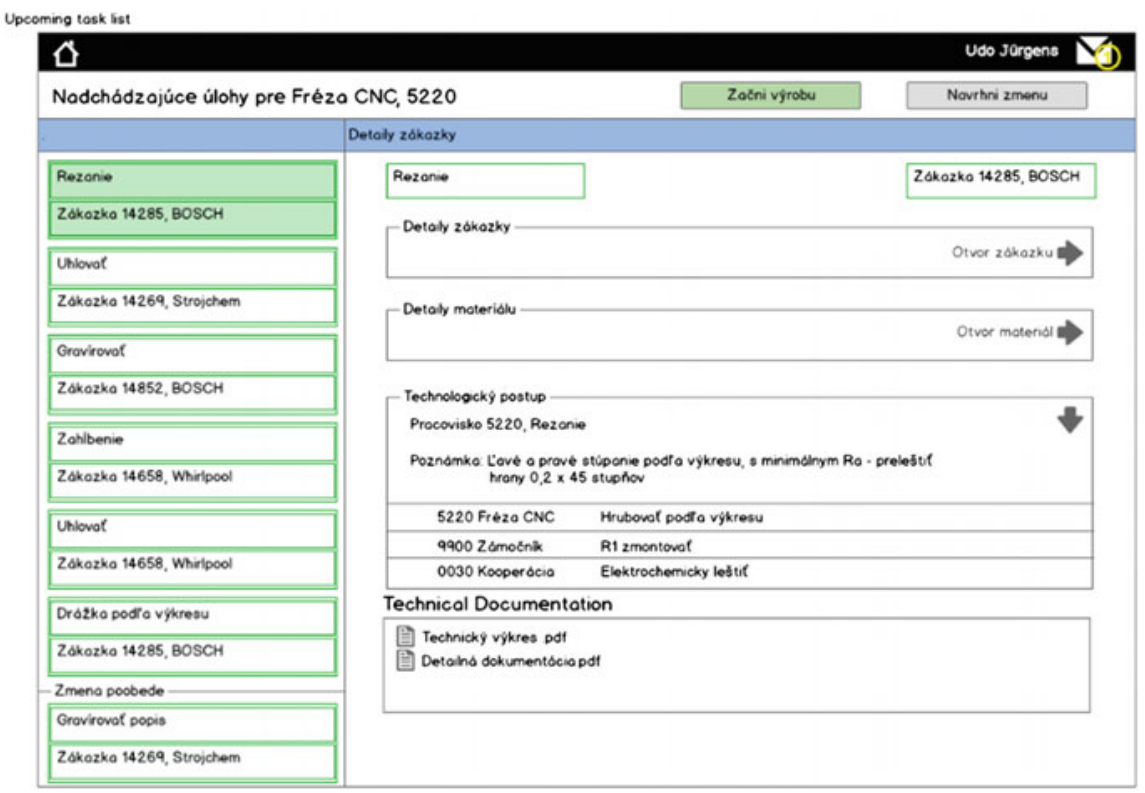

Fig. 4.3 Provision of upcoming tasks and production information for individual workplaces

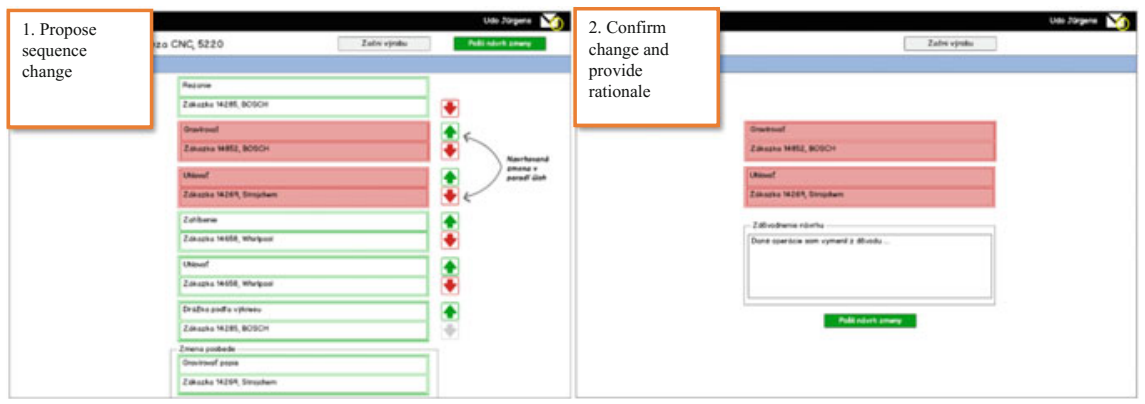

Fig. 4.4 Propose change in task list to optimize workplace-related task sequence

The Kanban View also allows checking details for certain views. For instance, Fig. 4.8 displays the details for "Technological Planning". Here, the technical operations need to be defined for two orders, for one order the required material needs to be defined, and for three orders the technical documentation needs to be created. When selecting a certain operation (see Fig. 4.8), details are displayed on the right-hand side (e.g. KPIs like average time for task, frequency of tasks, start time). 


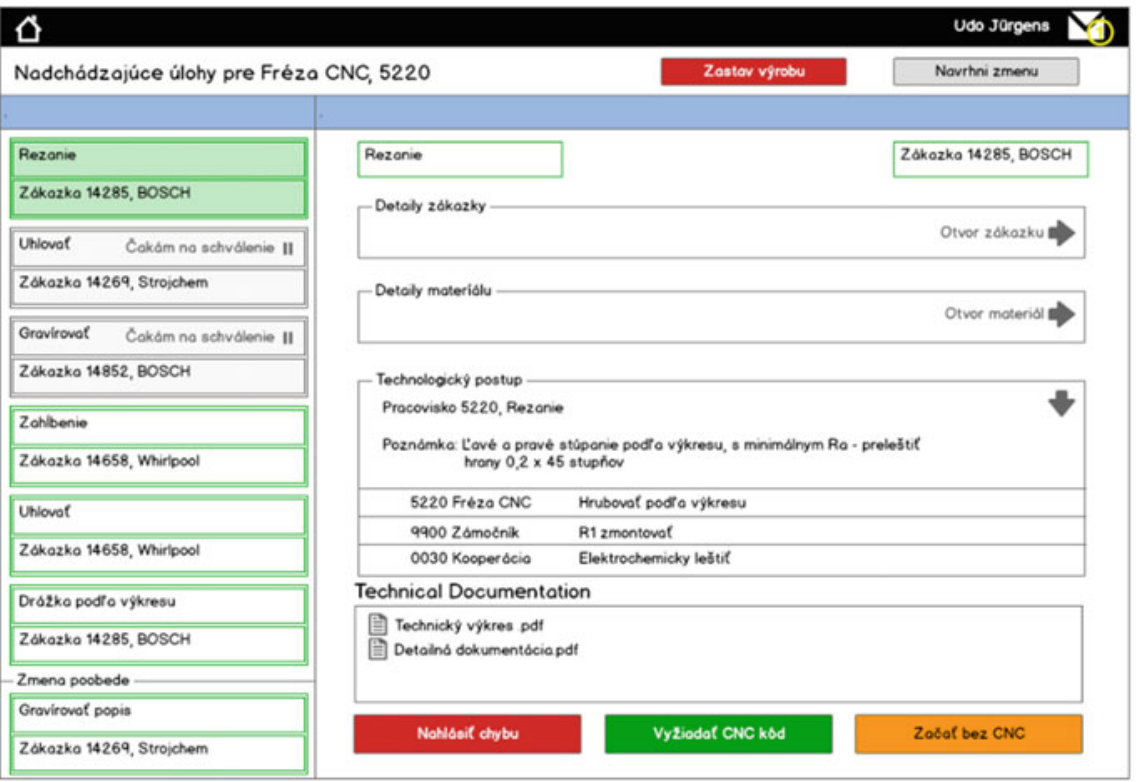

Fig. 4.5 Request CNC code

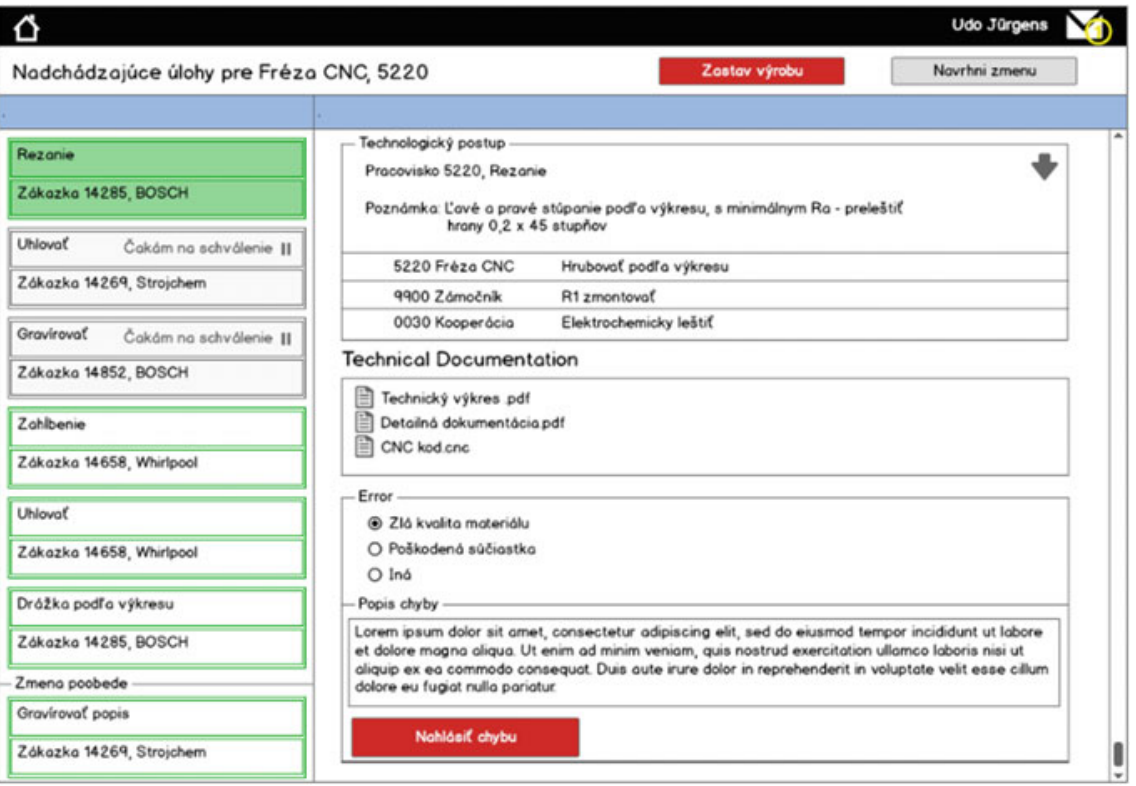

Fig. 4.6 Report error 


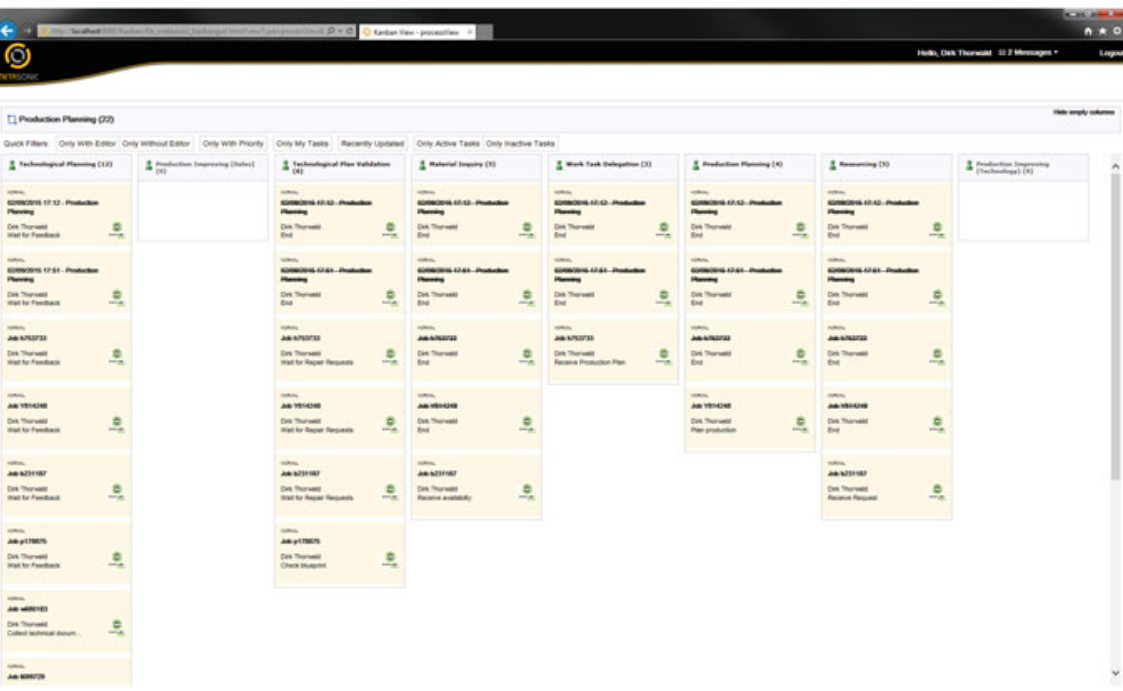

Fig. 4.7 Management Kanban View-overview

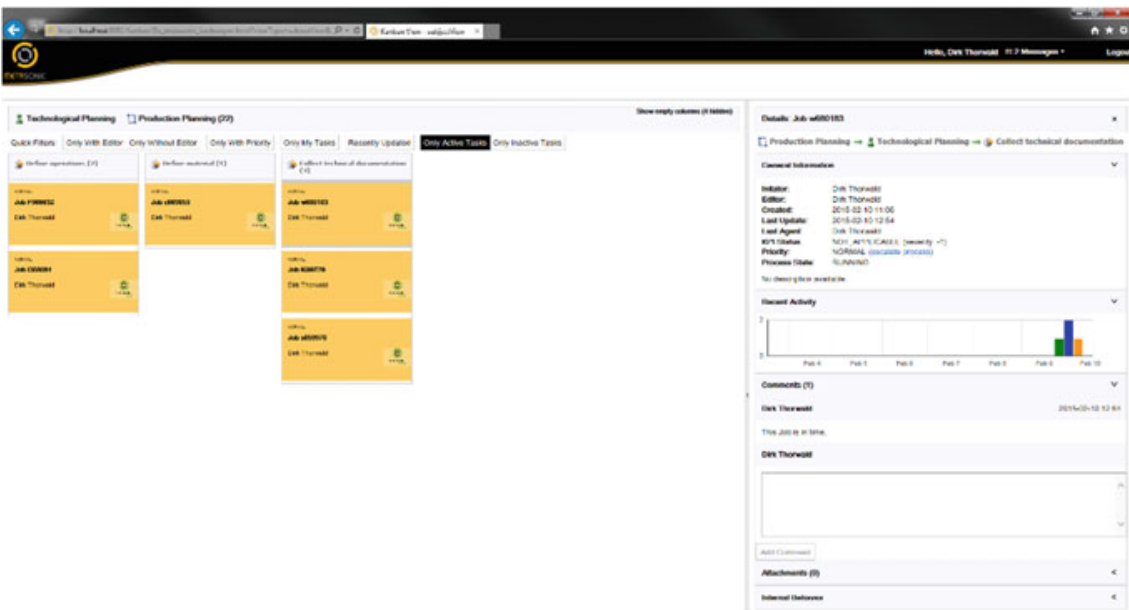

Fig. 4.8 Management Kanban View—details related to technological planning

\subsubsection{Reframing S-BPM Models}

The results of the initial analysis and design phase have been reviewed internally and by external auditors from the project-funding agency. The critical feedback related to the initial solution design comprised the following two aspects: 
- The additional value of the S-BPM solution compared to existing standard technologies was not immediately understood

- The potential change and improvement due to the S-BPM solution could not be identified with respect to people-centred workplace (re)design

Additionally, Company A started in parallel a new project for implementing a state-of-the-art production management system. The feedback and parallel developments required to highlight the benefit and additional value of the S-BPM project developments and a clear separation of concerns. This triggered a change in perspective. Starting from the S-BPM solution, the researchers from the University partner proposed an alternative, innovative approach to S-BPM modelling. Instead of modelling subject in terms of coarse grain organizational roles (cf. Fig. 4.1 "Production Manager", "Technologist"), the researchers proposed a more fine-grained approach focusing on behaviours like "Plan Validation", "Material Inquiry", or "Error reporting". This behaviour-oriented approach to S-BPM modelling structures organizational patterns in a more fine-grained way and depicts the required communication for alignment between behaviours. A part of the alternative approach is depicted in Fig. 4.9 which shows the "Production Planning Process" and its interfaces to "Manufacturing Preparation", "Manufacturing", and "Quality Control".

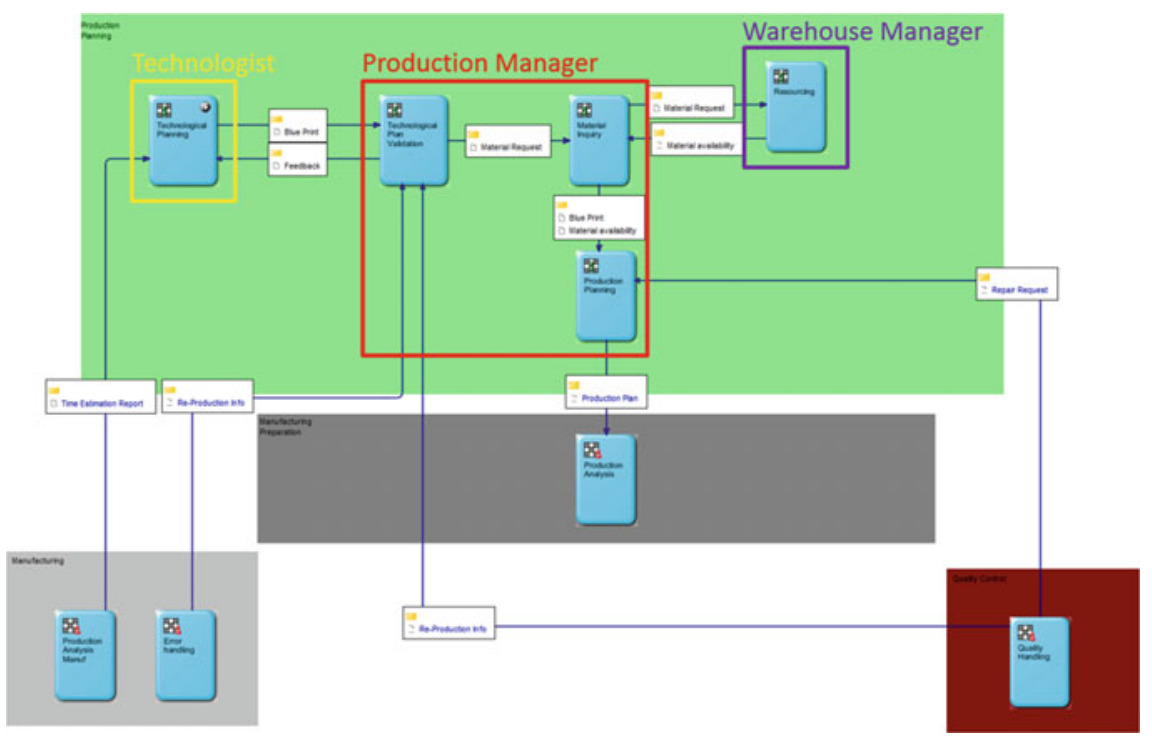

Fig. 4.9 Reframed-production planning process 
The original (role-centred) process design and the behaviour-centred process design are different with respect to the following aspects:

- The original production process is divided into four separate processes

- The amount of subjects increases in the behaviour-oriented approach due to the fine-grained modelling of functional behaviours as subjects. Overall, the amount of subjects increased from 7 to 17 subjects

- Internal behaviours are simplified and the amount of modelling elements for each subject is reduced. This is due to the decomposition of behaviours into functional entities ( $\rightarrow$ similar to encapsulation, modularization in software engineering).

In S-BPM roles are used to aggregate subject behaviours. Taking the original role-based approach, the role and the subject are potentially the same. Within the new behaviour-oriented approach subjects represent "responsibilities", or "functional behaviours" that are aggregated by certain roles. The fine-grained modelling approach supports the flexible assignment of responsibilities to certain roles and organizational actors. Thus, rights and duties related to an employee may be flexibly defined and dynamically changed based on, e.g. varying competences and qualifications. For example, experienced workers may handle errors themselves, whereas novices need to communicate with the production manager.

Furthermore, the approach allows generating competence profiles for certain workers based on their role-subject assignment. Within organizational development projects such behaviour-oriented models could be used to represent the as-is and to-be situation. Changes could be revealed and supported with respect to (1) the organizational structure in terms of authority and responsibility, (2) personnel development or (3) process adaptations.

\subsubsection{Soliciting Early Feedback}

The solution design and development has been accompanied by formative evaluation activities. Formative evaluation activities are typically conducted during the design and development phase of a project. The formative evaluation design for this case comprised several elements

- Short description of the evaluation element

- Functionality related to the evaluation element

- Technical key questions to be resolved

- User interaction key questions (Usability, Usefulness, Social Acceptance)

- Relevant stakeholders (users, technology provider, evaluators)

- Evaluation methods to be applied

Technical key questions have been discussed and resolved in dedicated developer workshops. (Social) Acceptance questions have been discussed with workers 
and the management in specific focus groups. In a third step, user tests addressing usability, usefulness and acceptance have been conducted with a prototype.

\subsubsection{Feedback Through Focus Groups}

The worker-specific focus group involved overall seven workers representing different types of workplaces involved in the solution design $(3 \times$ Milling Machine, $1 \times$ CNC Developer, 1× Technologist, 1× Quality Assurance and 1× Assembly). In this focus group, the regional IT Consultant presented the mock-up prototypes of the user interfaces dedicated to support the daily operations of workers, internal communication on errors and task changes, as well as power metering and location tracking support (cf. Sect. 4.2.1).

In general, the workers declared interest in the prototype supporting their daily work. They appreciated that the prototype enables summarizing their daily work plan, and thus they will have an opportunity to prepare better for upcoming tasks, especially with respect to work tools and required material.

Regarding the CNC request support functionality, the workers agreed that it will be very beneficial to see in advance whether the CNC program exists for the upcoming tasks. Furthermore, they appreciate the opportunity to request this program in advance. However, the workers mentioned that, at the moment they need to decide whether a CNC program is required when a production task is assigned to their workplace. One worker suggested that the technologist should already assess whether a CNC program is required and ensure its in-time availability at the shop floor workplace.

With respect to the provided error report functionality the workers provided the following feedback: Errors related to individual components are approximately 30$40 \%$. Less serious errors are fixed by experienced workers while more serious errors need to be consulted with the production head who proposes a solution. They appreciated the recording of errors and would also like to be able to reuse this knowledge in future production situations. As common errors the workers identified the following categories:

- Incorrect technical documentation causing errors in the production

- Material error (5\%)

- Error from the previous operation (previous production step)

- Error in the operations order

In addition to the error handling, workers may provide a production report to the planning department. This enables reviewing differences between planned time and real production time. The workers agreed that this opportunity may improve planning and increase the efficiency handling of an entire order. However, they noted that

(Time estimation) is a matter of understanding. When he (technologist) doesn't want to understand it... he can come, he can observe and notice what actually is required to conduct a manufacturing operation... 
I have disputes with technologists...they never come to me asking: Why do you scold me? They do not want to hear an answer. However, I would tell them.

Time estimation works as follows - a technologist writes down $2 \mathrm{~h}$, a worker works $4 \mathrm{~h}$. The technologist gets back the manufacturing protocol and he corrects $4-3 \mathrm{~h}$...but the worker doesn't know. Then they make some statistics claiming that workers miss $10 \mathrm{~h}$. The technologist is not forced to change the time estimations. They are not reflected in the final product price. The pressure for the technologists is missing...

The technologist is limited by the sales price. Based on the actual production time the future price should be negotiated.

Concerning the location tracking of parts and the real-time production state tracking, the workers provided positive feedback, especially the assembly department. This is reflected in the following statements:

This kind of information is useful for the assembly or for cooperation, i.e. departments where tools and parts are collected. The current state is crucial for the assembly to plan ahead. When $80 \%$ is already produced, it is goof to know where the remaining $20 \%$ reside. Furthermore, it is useful for reporting urgent matters (e.g. delays). However, related to tool tracking, it is not always possible to determine according to technological blueprint whether a dedicated tool is needed for the assembly. Therefore, I could need information on the location of certain tools.

It is always good to know what I can expect and plan...

The workers declared concerns regarding power consumption monitoring of machines. They had concerns on the usage and interpretation of the measured data. Especially, the workers were afraid that the management could use the numbers to better measure the individual productivity of workers at a certain workplace. They recommended to carefully interpret the data, since different tasks require different effort in time for preparing task accomplishment. Hence, the operation time of the machine should not be the only indicator of worker productivity. A worker stated to that respect

It depends how the management will evaluate this kind of data...if it is measured or not, we will work in the same way...given...the management will not take the power consumption as the final number. Out of $8 \mathrm{~h}$ the spindle might only spin 1 and half hour.... the remaining time might be required for preparation....

In the management focus group, the regional IT consultant presented both, the mock-up prototypes for workers on the shop floor and the intertwined interactive management view, so called Kanban View (cf. Sect. 4.2.1). The focus group with the management comprised three managers, the sales manager, the production manager and the manager of technological department.

With respect to the provision of feedback and reports related to time estimations the management indicated the following: Feedback on the estimations has to be justified. A common challenge is that the actual production time will always differ depending on workers' experience and work practice. Some workers note shorter production times than real, others overstate the time actually needed for a certain production task. However, the actual time should be measured and taken into account within future planning cases to ensure profitability of production offers. 
Regarding the proposal of changes related to upcoming task list at a certain workplace, the management noted that such a mechanism is already implemented, but not supported by an IT system. Change proposals are basically noted on the paper-based blueprints, either with stroking/deletion or some notes. The change in the order of operations or tasks is also possible, but usually occur based on the initiative of a supervisor. Furthermore, the management confirmed that the communication does not work properly (e.g. between technologist and workers). The management appreciates a solution to support transparent communication between the different workplaces involved in production orders.

The designed Kanban View for the management allows tracking the current state of production, e.g. checking what is in preparation, currently operated at a certain machine, or in quality control. According to the perception of the management, the Kanban tool may help to monitor the current state of production. Furthermore, the management recognized that the system might also help to better support less skilful workers in task planning and during task operation.

\subsubsection{Feedback from User Tests}

User tests were conducted involving three workers on the shop floor, in order to assess the tablet interface already presented within the focus group. The tested interface was developed by Metasonic and comprises the functionalities encoded in the initial mock-up prototypes. However, the look and feel differed slightly from the prototype, and only a reduced set of functionalities was available. In the user tests, actual data from production were used to simulate a realistic work situation. Furthermore, the tests were conducted at the actual workplaces of the users using a portable tablet device.

During the test users were requested to "Select an upcoming task" from the "In Preparation" list and subsequently (a) check the details, (b) check the required materials, (c) check the operation description as well as (d) the documentation. Furthermore, users were asked to "Request the CNC Code", "Check part location", "Start production", "Prepare a machine for predefined technological operations" and to "Stop the production of a current task".

The observation of the users during task accomplishment revealed the following: The younger users (age 35 and 40) were able to accomplish the tasks within a few seconds. However, an older user (60) struggled to navigate through the application, since he was not used to tablets at all, and the basic user interaction concepts were not familiar for him. Furthermore, the older user insisted from the very beginning on the existing "paper based work style" he was used to work with-although he agreed that all the information required to fulfil a certain work task is provided within the application. Related to the interaction with the system, the observations showed that two users were unable to determine the location of a part on the shop floor, because they did not find the related user interface element. Moreover, within the preparation of work task, workers required a program path not provided in the user interface.

In summary, user 1 declared that the user interface was easy to use and to navigate through, although he thought that information should be structured in a 
better way, and put in a single view, so e.g. he does not need to click to see the detail of technological operation. In addition, user 1 appreciated the part-location tracking support, and thought that this system would help better to communicate with managers. User 2 noted that he would appreciate to see the list of predefined tools in the operation detail screen as well as their availability and location.

Aside from interaction issues, significant performance issues in terms of long response times could be observed during the user tests. This performance issues are related to deploying the application on an old test server with limited capacity. Furthermore, in two user tests the part location was not correctly retrieved. Hence, system failures occurred and the system crashed.

\subsubsection{Feedback from User Interaction Questionnaire}

After each user had accomplished the tasks, they were asked to fill in a questionnaire. Using the questionnaire participants reported the perceived usefulness and the perceived ease of use of the system as well as aspects concerning social acceptance. Additionally, they have been asked to list most negative as well as positive aspects. In total, three people filled in the questionnaire.

\section{Listed negative aspects:}

I think the iPad is not suitable to be used in the manufacturing environment. It could be easily damaged or crashed. As well I think, that most of my colleagues won't be able to easily use the device, but for younger it won't be problem.

I think that this system is more suitable for bigger productions than TC Contact.

For the work we are doing it sufficient to use the old system we're used to work with.

One person also listed the following positive aspect:

Using this system I would definitely have better overview of my tasks, where the part is located on the shop floor, when production begins and who is working on it.

The users were asked to indicate how unlikely or likely several statements were on a scale from 1 (unlikely) to 7 (likely) or "Not applicable". The statements were clustered along the following dimensions:

1. Perceived usefulness

2. Perceived ease of use, and

3. Social acceptance of "Process Automation Support" prototype

1. Perceived usefulness: The younger users (age 35 and 40) indicated to some extend at least that the "Process Automation Support" prototype is useful and would increase their productivity. The older user (age 60) did not perceive the system to be useful at all. All users rated the prototype more or less unlikely to improve their productivity.

2. Perceived ease of use: Answers related to the ease of use indicated a positive trend. The users seemed confident to find it easy to learn to operate the prototype successfully. The older user did not find it very likely that the device could be easy to use for him or that the system would be flexible when interacting with it. 
3. Social acceptance: In addition to usefulness and ease of use, the questionnaire included items related to social acceptance. All three users indicated a positive trend to having the knowledge, but not necessarily the resources to use the system. Concerning emotions when using the "Process Automation Support" prototype, all the users stated that the system was somewhat intimidating to them. They also would hesitate a little bit to use the system, since they fear to make mistakes they cannot correct.

The results of the user tests with workers need to be interpreted carefully, since only three users interacted with the system. Nevertheless, the users seemed confident to be able to learn how to operate the system successfully. With respect to the usefulness and the social acceptance of the prototype, improvements need to be implemented in the final system. In particular, older users seemed reluctant to use such a system. As consequences and measures, the following topics were derived to be carefully considered within the case study implementation:

- Performance optimization of worker-related user interface

- Provision of path to CNC code within work task preparation view

- Increased visibility of user interface element for part location

- Facilitation of part location retrieval

- Provision of protective cover for tablet in order to decrease workers' fear to crash the tablet

- Clear and transparent communication of the usage of measured power metering data to workers in order decrease resistance and fear

- Addressing adequate workplaces and workers with tablet solutions-it seems older users are likely to be resistant to change

\subsection{Case Implementation}

In the case implementation the process models, the interfaces to existing systems, the set-up of required hardware and the organizational implementation were fine-tuned at Company A. In this section, especially the organizational and technical implementation will be described.

\subsubsection{Organizational Implementation}

\subsubsection{Selected Workplaces}

Overall, five workplaces (machines) on the shop floor were selected. The aim of the selection was to choose a set of the principal workplaces most frequently involved in the company's production operations. At each workplace, one worker is operating the machine within a shift. The selected workplaces are listed below (Fig. 4.10): 


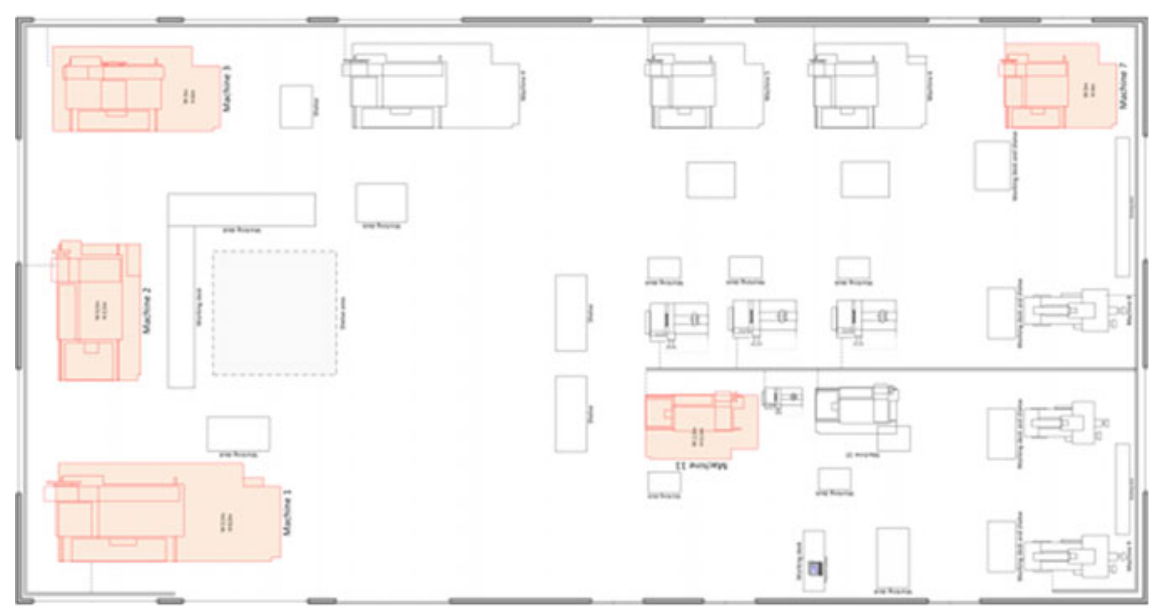

Fig. 4.10 Selected workplaces for the case implementation at Company A

- Turning Machine Mazák

- Milling Machine MCFV1060

- Milling Machine G. Master

- Milling Machine Huron

- Milling Machine DMG DMF260

In the case implementation, the selected workplaces have been equipped with iPod touch devices to detect the location of active trackers related to parts (cf. Sect. 4.3.2). Furthermore, iPads were installed at these workplaces as interface to the provided work support system. The production management accessed the system via its office PCs.

\subsubsection{Implemented S-BPM Process Support}

The implemented S-BPM solution comprises overall seven process as depicted in Fig. 4.11. Subsequently, these processes are described in more detail. In general, Production Planning initiates Manufacturing Preparation. Manufacturing Preparation triggers the Manufacturing process that may result in Feedback on work sequences, work durations, work plans, errors and quality, and necessary steps to repair parts. Furthermore, a "location tracking" process is running continuously to infer the location of parts relevant for "Manufacturing Preparation" and "Manufacturing". Aside from the six core processes, the Master Data Management process supports the configuration of available workplaces and devices.

Production Planning is the partial process that initiates a certain production process. Thereby, the production manager assigns the tasks to certain workplaces and releases the work order for manufacturing. The basic planning and definition of operations and material related to an order is done within the ERP system (Dialog 3000) of Company A. The "Production Planning" subject interfaces the ERP system and automatically retrieves relevant process data based on the order ID. The "Production Planning" subject furthermore encodes the configuration of the 


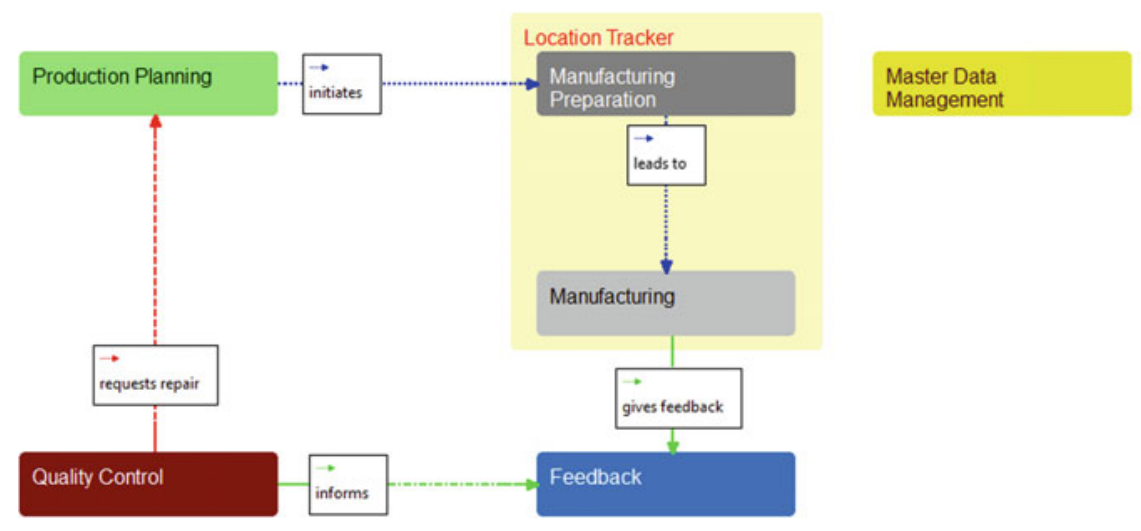

Fig. 4.11 S-BPM process overview

corresponding location tracker for an order. The "Work Task Delegation" automatically distributes work tasks to the defined workplaces. Thus, workers will see the assigned tasks in their list of upcoming work tasks (cf. "Worklist Checking" Fig. 4.12) on their workplace-related tablet.

The tablet interface displays a list of upcoming tasks, tasks in preparation and tasks already in production (subject "Worklist Checking"). In case a worker has more than one upcoming task he can proceed with the following actions:

- Display task details

- Propose a change to task order

- Accept the task

If a worker proposes a change to the sequence of the worklist, the "Worklist Change Approving" subject assigned to the production management is notified. Upon the reception of a change proposal, the production management may evaluate it, and either accept or deny it. Afterwards, the worker will immediately receive the manager's decision.

In case a worker does not propose any change, he may continue with preparing the operation of the work task (subject Work Task Preparation-cf. Fig. 4.13). In the preparation step, a detailed task description is shown, containing the following information:

- Name of the order/task

- Pieces to be manufactured

- Material

- Predefined technological operations

- CNC code path

- Technical drawing (part blueprint)

- Part location 


\section{Production Planning}

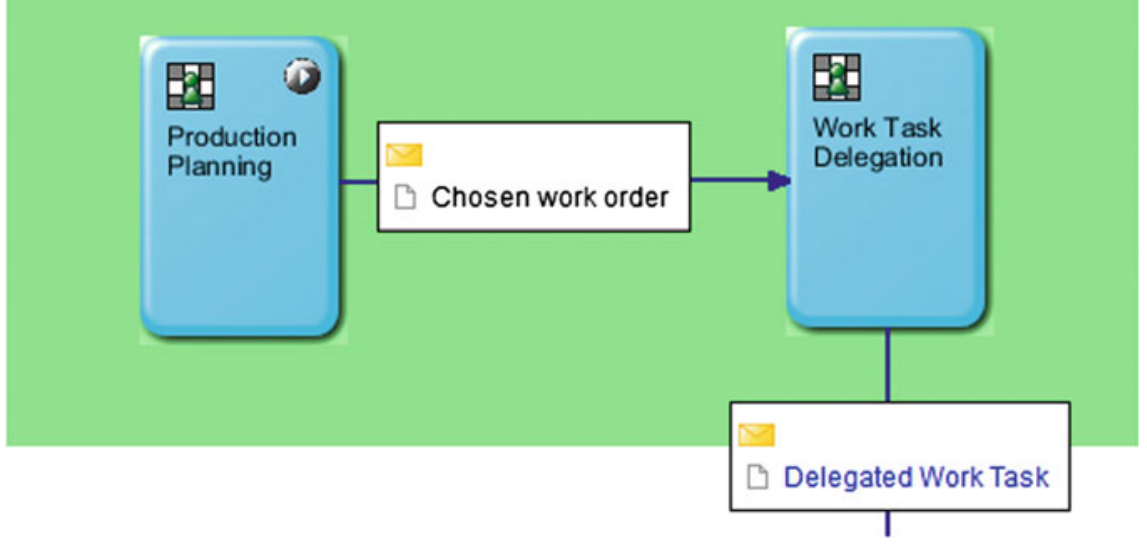

Fig. 4.12 Production planning process

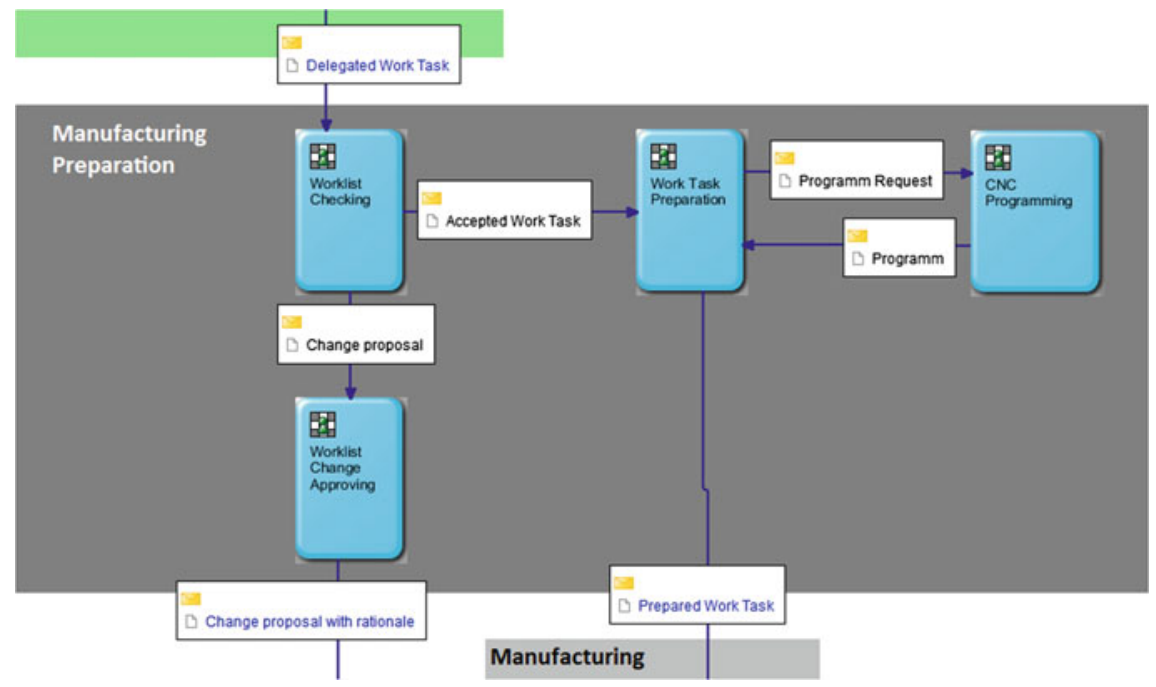

Fig. 4.13 Manufacturing preparation

If the required $\mathrm{CNC}$ code does not exist, the worker can decide either to request CNC code from the technologist or to write it on his own, before starting the machining operations (Fig. 4.13-subject "Work Task Processing").

When a worker starts a production task (subject "Work Task Processing" —cf. Fig. 4.14), the processes of measuring power consumption of the workplace-related machine is initiated. Every minute the amount of the current power consumption is 


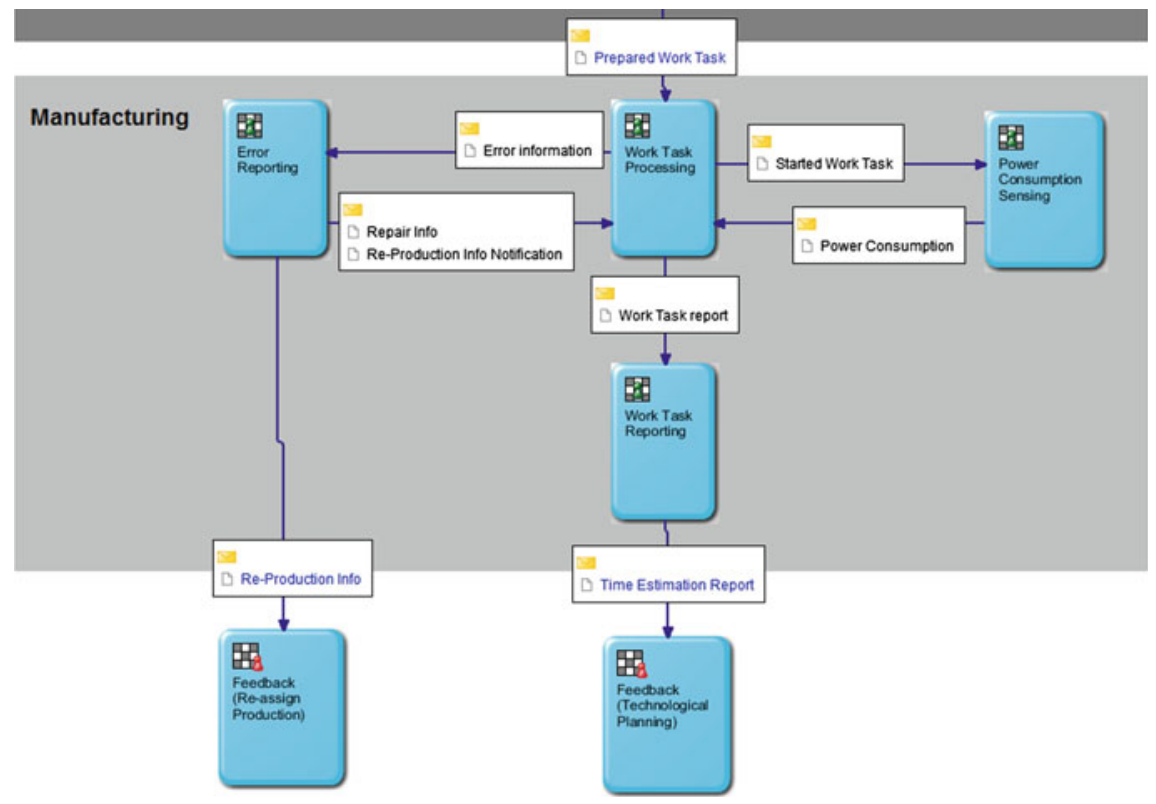

Fig. 4.14 Manufacturing process

retrieved via an OPC UA-enabled power consumption metre (subject Power Consumption Sensing). This data is stored in a dedicated business object of the workflow system and allows the management checking the current status of a machine (Standby, Rotating, Changing tool, Full load). Furthermore, the collected data could be used to analyze actual times of machine operations related to pre- and post-processing times. This information could be used for further improving time estimations of operations.

After a machining operation is started, the worker is able to proceed with one of the following actions:

- Report error (Subject Error Reporting)

- Report completion of manufacturing task (Subject Work Task Reporting)

When a worker discovers that a manufactured part is defective, he is able to report that situation with his tablet. After clicking Report Error he can send detailed information to the manager about the defect. In addition, he may propose steps for fixing the defect, or request discarding the part and restarting the manufacturing process.

When a machining operation is finished, the worker indicates this status by pressing the Stop Production button on his tablet application. Subsequently, the measurement of the power and the general work task reporting form is shown with 
the work report summary. In this report form, a worker may add his feedback regarding the manufacturing operations of the part.

In parallel to the manufacturing preparation and manufacturing processes a "Location Tracker" process is running. This process updates the location of orders within the shop floor based on active trackers and beacon devices (iPod touch) which transmit the location of trackers to the central processing system.

The update interval of the tracking may be configured in the process model. In the test scenario, an interval of $5 \mathrm{~min}$ was chosen.

The manually and automatically gathered data are summarized in the end of each operation. Thereby, a worker may provide feedback to different workplace aspects

- Reporting change proposals (including the rationale for the change) to the technologist and sales staff

- Time estimate comparison - the actual time spent on manufacturing versus the time initially planned by the technologist

- Description of the error with proposal to repair/restart production

\subsubsection{Technical Implementation}

The technical case implementation considered the development and set-up of the required hardware and software components at Company A. Figure 4.15 sketches the system architecture in term of hardware and software components and the mutual communication on a general level. Basically, each selected machining workplace is enriched with a beacon device, a tablet for digitized work support and a power consumption metre.

Custom trackers have been developed by the hardware developer of the project. The trackers promote their presence via Bluetooth 4.0 to beacon devices nearby. They integrate a Bluetooth 4.0 RF frontend, enabling the micro-controller to

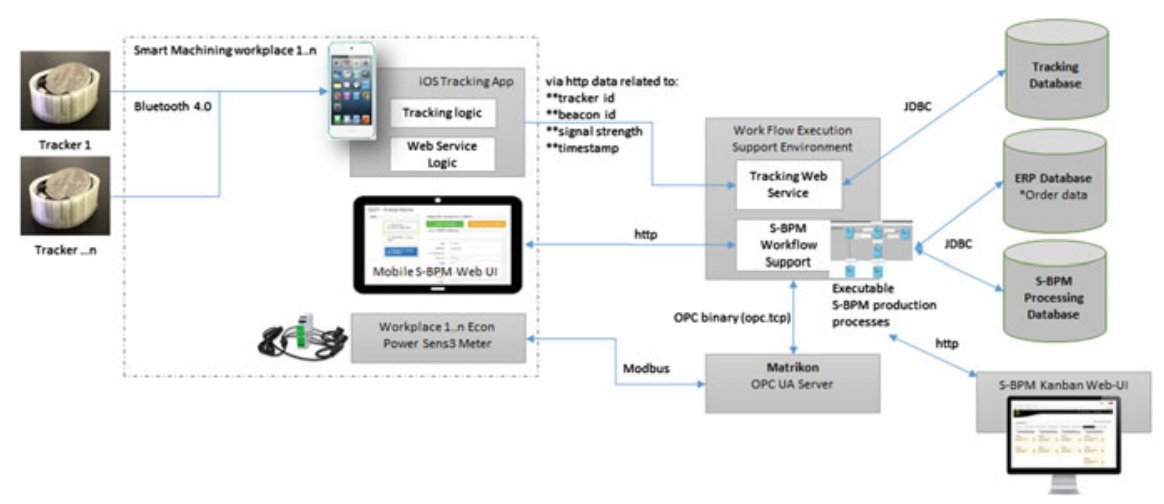

Fig. 4.15 Company A—system architecture 
communicate wirelessly with a range of approximately $5 \mathrm{~m}$ with other Bluetooth devices. Each tracker is equipped with four LEDs to indicate whether the unit is powered, whether it is functioning correctly or not, and whether it is in proximity range of a beacon. Location trackers broadcast every minute a signal that encodes their identification number, to be detected by beacon devices.

As beacons Apple iPod Touch devices equipped with iOS version 9.2 are used. An iPod app for gathering and transmitting data was built using the Objective-C and iOS Framework. The beacon device represents the workplace it is attached to for location tracking purposes. When the beacon receives the signal from a paired tracker, it passes the tracker ID (encoded in the signal) via a Web service to the backend, together with the signal strength in $\mathrm{dBm}$. The lower the value of signal strength, the greater the distance of the tracker from the beacon device (workplace) and vice versa. This information is used by the Web service to derive the location of the workpiece in terms of the beacon ID that has the highest signal strength for a given tracker. The configuration of the beacon-workplace mapping and the tracker ID and order ID mapping is supported via dedicated S-BPM process logic.

Additionally, workplaces were equipped with non-invasive power measurement sensors. Specifically, Econ Sens3 Power metres were selected since they enable non-invasive power measurement and the accessibility via the Matrikon OPC UA Server. Thus, S-BPM process steps may retrieve data from the sensors via OPC UA refinements (cf. Sect. 3.1.2). The measurement is carried out by applying the Hall effect, without requiring any intervention in electric circuits of the device. The metre is installed on the device feed phases, and its measurement loops are wrapped around each of the three phases on the machine. Parameters such as voltage, frequency and machine capacity can be measured using this device. The measuring device is connected to the network via a standard RJ-45 connector and communicates based on standard Modbus TCP with the OPC UA Server.

The measurement of the current power consumption was intended to infer the machine status and support the automatic determination of preparation-, machine operation- and post-processing times. For inferring the machine status, heuristics for reference values were required. Thus, for each type of machine, measurements were performed to infer the status. For instance, Fig. 4.16 shows measurement heuristics and machine states for the workplace DMG DMF260.

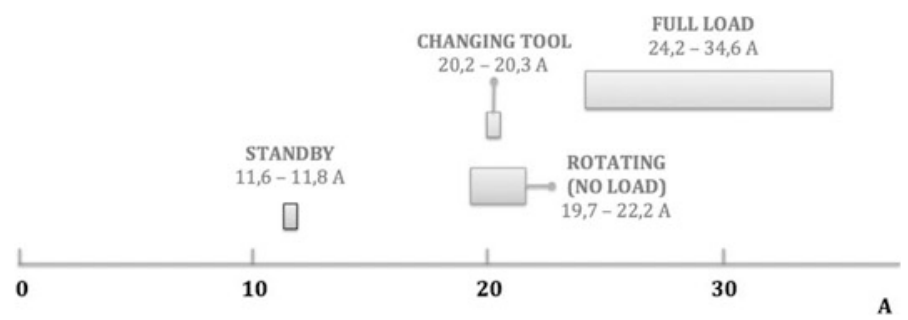

Fig. 4.16 Relationship between machine status and power consumption 


\section{7 - Fréza Huron}

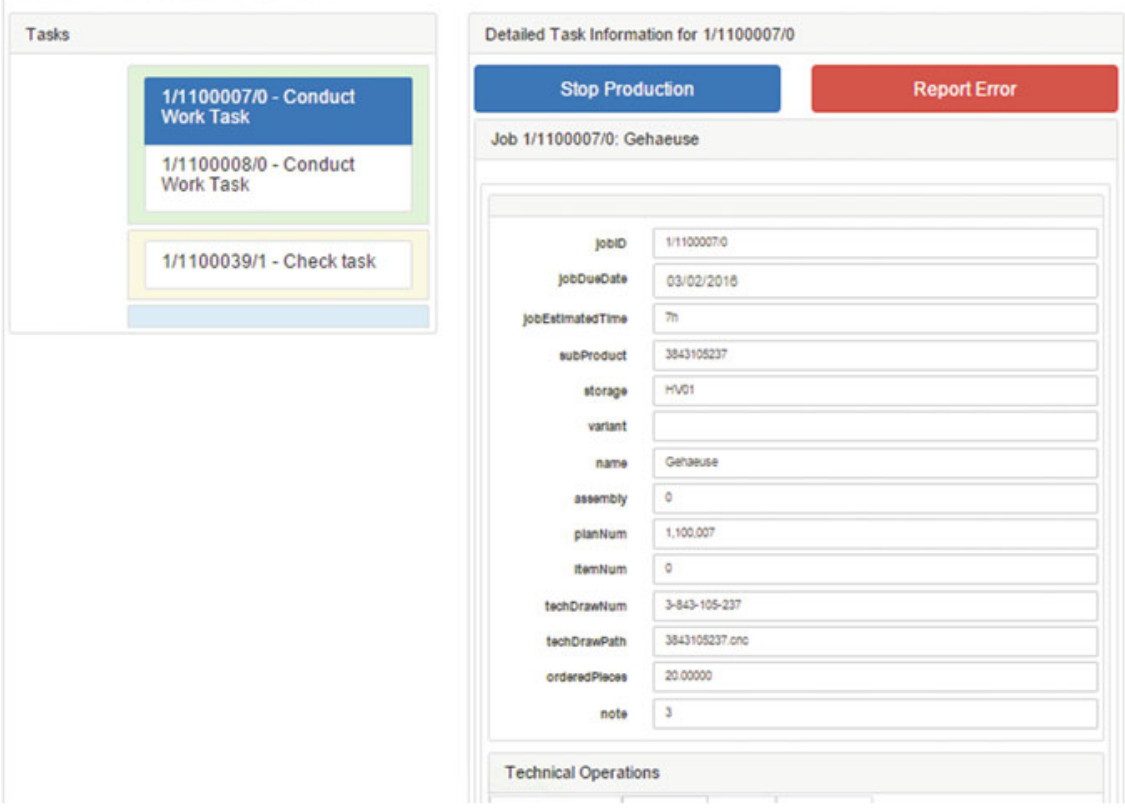

Fig. 4.17 Tablet view for producing a part

A third enrichment of the workplace represented the digitized work support via a tablet and a responsive Web-based workflow user interface. The development of the responsive Web-based user interface applied the presented approach by Kannengiesser et al. (2016). Therefore, in addition to the core production process logic, the user interface logic was modelled within S-BPM UI processes. These S-BPM UI processes serve as basis for the Metasonic Suite to generate dynamic Web pages using the bootstrap framework (http://getbootstrap.com) for responsive design.

Although the look and feel of the developed tablet application differs from the initially developed mock-up prototypes (cf. Sect. 4.2.1), it encodes the main functionalities defined. An example view display when producing a part is given in Fig. 4.17.

Within the task list on the left-hand side of Fig. 4.17, each colour-coded rectangle group tasks into different manufacturing states

- The blue rectangle groups tasks which are awaited to be manufactured

- The yellow rectangle groups tasks for which the process of preparation began but production has not yet started

- The green rectangle groups tasks for which manufacturing has already started 
In comparison with the workers, the management accesses the S-BPM processing support via its office PC and the installed Web browser. The developed Kanban UI (cf. Figs. 4.7 and 4.8) represents a Web application accessible via any Web browser. Again, this is a custom interface developed for the case, since the generic Metasonic UI was deemed too rigid and complex.

The "Workflow Execution Support Environment", the "Matrikon OPC UA Server", the "S-BPM Processing" and "Tracking" database were set up and configured on a central server. Moreover, a separate network was installed for the communication among the beacon devices, power metres, tablets and the server components.

The interface to the ERP system introduced in parallel was provided via dedicated database views, which were queried within the S-BPM processes using so-called "DBReader refinements" in Metasonic Suite. The S-BPM processes interface the tracking logic via a Web service call within a dedicated function state.

\subsection{Case Evaluation}

In addition to formative evaluation activities (see Sect. 4.2.3) informing design and implementation, a summative evaluation framework to evaluate the goal achievement in this industrial case was developed and applied (Fig. 4.18).

This framework defines core case evaluation elements with respect to the case goals, evaluation methods to be applied, and evaluation dimensions. Each case evaluation element comprises (1) a short description, (2) relevant stakeholders, (3) a mapping between goals and IT functionalities related to the case evaluation element, (4) evaluation questions related to the goal achievement, (5) evaluation

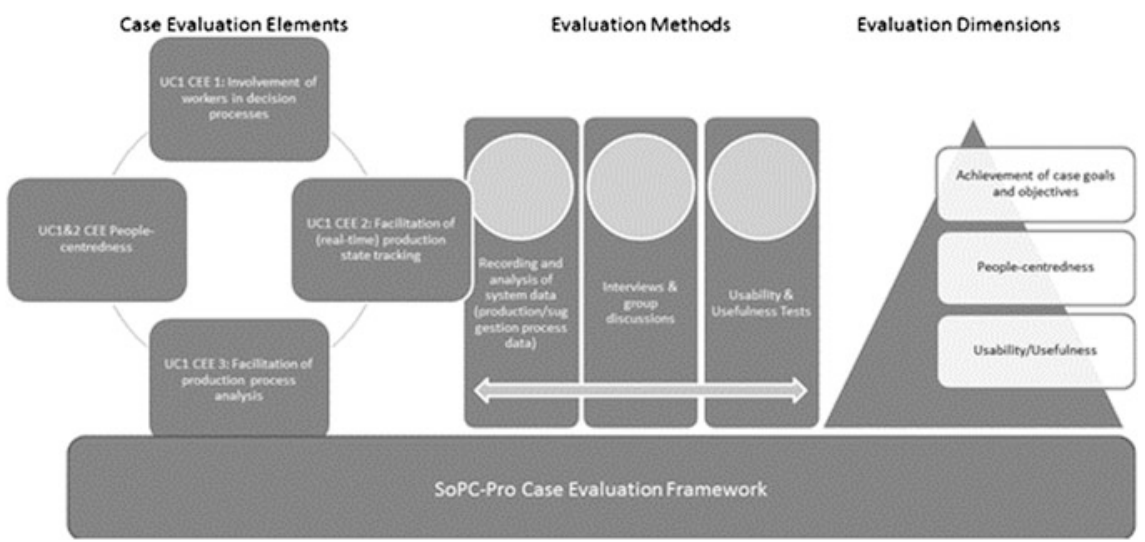

Fig. 4.18 Case evaluation framework for Company A 
questions related to usability and usefulness, and (6) data collection methods to be applied. The following four case evaluation elements were defined:

- CEE 1: Involvement of workers in decision processes

- CEE 2: Facilitation of (real-time) production state tracking

- CEE 3: Facilitation of production process analysis

- CEE 4: People-Centeredness

CEE 1-3 mainly address the evaluation dimension "Achievement of case goals and objectives". The evaluation dimensions "People-centeredness" and "Usability/Usefulness" are orthogonal to CEE 1-3. People-centeredness includes developing conditions for higher employee involvement in the production decision-making process. The implemented features were designed to enhance the worker engagement and thus contribute to their self-fulfilment. People-centeredness can be characterized by (1) the People-centeredness of the implemented solution, and (2) the People-centeredness of the project implementation process itself. The dimensions of usability and usefulness combine assessing the solution's practical aspects and its contribution to perceptible changes. In terms of usability, a user is supposed to assess the ease of system operation. For the usefulness dimension, the tool or solution's contribution to the user's performance, productivity and effectiveness is addressed.

\subsubsection{Evaluation Steps and Procedure}

Qualitative and quantitative data collection and analysis methods were selected to evaluate the case. Subsequently, the evaluation instruments are described. A technology acceptance questionnaire was applied. This questionnaire considers usability and usefulness aspects. In addition, semi-structured interviews were conducted to gain grounded insight in the goal achievement and the people-centeredness of the implemented organizational procedures and tools. Overall, employees at Company A received training to use the provided IT-based work support and used the system in their work context for 2 weeks.

\subsubsection{Technology Acceptance Questionnaire}

A standardized questionnaire was used to assess the technology acceptance of the implemented solution. The results of the survey provide general insights into the technology acceptance of the system from the users' point of view. The questionnaire took into account the following dimensions:

- Perceived usefulness

- Perceived ease of use

- Social acceptance

- Behavioural intention to use the system 
Each dimension was operationalized through several statements (items). Users were asked to read each statement and indicate to which extend he or she agrees on a five-point answering scale (absolutely agree to absolutely disagree). Since data from only nine people have been collected, the results of the statistical/quantitative data have to be interpreted carefully. More important, it has to be checked whether these results are consistent with the results of the in-depth qualitative data collection and analysis methods.

Printed questionnaires were distributed among nine employees, including managing director, production manager, technologist and six shop floor workers. The respondents were one woman and eight men. According to the age, the respondents could be divided into three age categories: 20-30 years old (one shop floor worker and executive director), 30-50 years old (four shop floor workers and production manager) and 50+ (technologist and one shop floor worker).

\subsubsection{Semi-structured Interviews}

The qualitative evaluation was operationalized via semi-structured interviews. A list of questions was set up according to the main aspects to be researched. The researchers followed two approaches - a high-level approach and a technical approach. The aim of the high-level approach was to gain insight into respondents' perception of and views on the particular case evaluation elements. The questions were therefore designed as open-ended, focusing on their understanding of and opinion on the feature's impact on performance and the opportunity to use it. The open-ended questions beginning with "how" allowed respondents to express a full, meaningful answer using their own knowledge or feelings.

The technical approach involved more particular, focused questions aiming at getting feedback on the practical use of the implemented features. Consequently, the questions were formed mostly as "have you ever", "what problems have you experienced", "how often have you", etc. They were supposed to provide information on the frequency, problems and (dis)advantages of implemented features.

\subsubsection{Summative Evaluation Results}

\subsubsection{Technology Acceptance}

Regarding perceived usefulness, the responses revealed the following: Three quarter of the respondents indicated a tendency for a disagreement regarding the perceived usefulness. About one quarter of the respondents stated an indifferent attitude regarding the perceived usefulness of the process support.

The perceived ease of use was judged as follows: Overall, one-third agreed that the provided system is easy to use. Another third was undecided. The remaining third disagreed with the ease of use. Taking a more detailed look on the items of perceived ease of use, especially learnability and understandability indicated agreement, while especially flexibility and controllability of the support revealed disagreement.

The social acceptance was assessed by the respondents quite diverse: Overall, around one-third indicated a positive tendency, one-third was undecided and 
another third indicated a negative attitude towards social acceptance. Furthermore, the statements towards the behavioural intention to use the system indicated that employees do not plan to use the system in the near future (six out of nine respondents).

In summary, the technology acceptance of the implemented work support was assessed as rather average and low, respectively. Although a user-centred design approach was applied within the project at Company A, organizational factors seemed to have a negative impact on the outcome. These factors will be discussed in Sect. 4.4.3.

\subsubsection{Case Evaluation Elements}

The case evaluation elements were investigated by applying qualitative semi-structured interviews. The qualitative analysis complements the quantitative analysis carried out with employees at Company A. The qualitative analysis provides deeper insight into the experience with the implemented solutions, and how the stakeholders perceived the developed features. Subsequently, the results for each case evaluation element are described.

CEE 1: Involvement of workers in decision processes

This element comprises the aspects depicted in Table 4.3. The aspects are detailed in terms of name of the feature, the role using the feature and a general description. Evaluation results with respect to the individual features are stated subsequently.

\section{Proposal of Changes to individual work schedule}

In general, respondents consider the option to propose changes to individual work schedules as useful. However, regarding the practical utilization and their experience within the testing phase the answers seem oppositional. Within the testing phase, the six shop floor workers reported no need to request any changes to their daily work schedule. Furthermore, the predominant organizational culture does not encourage workers to propose changes. Workers reported that they face a severe time pressure, try to meet deadlines, and follow what is proposed by the production manager and the technologist. The influence of the established long-term working system on the reluctance to propose changes was also stated by a technologist.

\section{Authorization of change proposals}

From the high-level point of view, the production manager assessed the feature as useful, since it digitally records all requests, and a loss of change proposals could be reduced. However, during the live testing phase, the shop floor workers did not request any particular changes of their work flow.

Autonomous decision to request CNC code

The ability to request a CNC program was possible in the formerly established work process at Company A. Now digitized, the shop floor workers tested and used the system in practice. The workers reported concerns on the immediacy of the 
Table 4.3 CEE1 aspects

\begin{tabular}{l|l|l}
\hline Feature & Role & Description \\
\hline $\begin{array}{l}\text { Proposal of changes to } \\
\text { individual work schedule }\end{array}$ & $\begin{array}{l}\text { Shop floor } \\
\text { worker }\end{array}$ & $\begin{array}{l}\text { This feature allows shop floor workers changing their } \\
\text { work schedules (tasks). Using this feature, a shop floor } \\
\text { worker is able to propose a change in the planned } \\
\text { production schedule for a particular workplace. The } \\
\text { proposed change must be approved by the production } \\
\text { manager, before entering the production state }\end{array}$ \\
\hline $\begin{array}{l}\text { Authorization of change } \\
\text { proposals }\end{array}$ & $\begin{array}{l}\text { Production } \\
\text { Manager }\end{array}$ & $\begin{array}{l}\text { When a shop floor worker proposes task reordering, the } \\
\text { production manager is notified with the change request } \\
\text { submitted by the worker. This feature allows him to see } \\
\text { the new task order proposal, compare it to the original } \\
\text { production plan, and decide to accept/reject the change. } \\
\text { After the decision, the shop floor worker is notified }\end{array}$ \\
\hline $\begin{array}{l}\text { Autonomous decision to } \\
\text { request CNC code }\end{array}$ & $\begin{array}{l}\text { Shop floor } \\
\text { worker }\end{array}$ & $\begin{array}{l}\text { Using this feature, a shop floor worker can decide whether } \\
\text { he needs to be supported with a CNC code from the } \\
\text { technologist, or he will write CNC code on his own }\end{array}$ \\
\hline $\begin{array}{l}\text { Context-sensitive error } \\
\text { reporting }\end{array}$ & $\begin{array}{l}\text { Shop floor } \\
\text { worker }\end{array}$ & $\begin{array}{l}\text { Shop floor workers are able to report an error occurring } \\
\text { during the manufacturing process. When reporting the } \\
\text { error, the worker is encouraged to describe the reason why } \\
\text { it occurred and propose a solution for fixing the problem if } \\
\text { a fix is possible }\end{array}$ \\
\hline $\begin{array}{l}\text { Work task reporting } \\
\text { worker }\end{array}$ & $\begin{array}{l}\text { This feature enables the shop floor workers to report the } \\
\text { overall progress of production. The main focus is on } \\
\text { gathering real production times so production managers } \\
\text { are able to compare the actual time consumed with the } \\
\text { time planned by the technologist }\end{array}$ \\
\hline Shop floor \\
\hline
\end{tabular}

response from the technologist. Since technologists are not permanently at their PC, workers fear to lose time when waiting for responses. Finally, especially younger shop floor workers reported their willingness to use the new system.

\section{Context-sensitive error reporting}

In general, shop floor workers perceived this feature supportive. Even if they consider it to be of greater benefit for bigger production facilities, workers stated that the feature could also be helpful in their context. However, also related to this feature the immediacy of the response was reported as a potential issue. The implemented process was configured to require the approval of the production manager for fixing an error. Thus, the workers reported that they lose time when waiting for an answer and that they prefer immediate (oral) feedback. Even though, five out of six workers considered digital recording of all reported errors as useful for further order improvements and analyses.

\section{Work task reporting}

The technologist and younger staff, including the executive director and one shop floor worker perceived the digitized work task reporting positively. Workers stated that the reporting should be considered for further planning and future price 
Table 4.4 CEE 2 aspects

\begin{tabular}{l|l|l}
\hline Feature & Role & Description \\
\hline $\begin{array}{l}\text { Display and autonomous } \\
\text { selection of work tasks }\end{array}$ & $\begin{array}{l}\text { Shop floor } \\
\text { worker }\end{array}$ & $\begin{array}{l}\text { The feature presents a prioritized list of work and } \\
\text { allows workers to prepare and conduct certain work } \\
\text { tasks }\end{array}$ \\
\hline Kanban Board & $\begin{array}{l}\text { Production } \\
\text { Manager }\end{array}$ & $\begin{array}{l}\text { The management may monitor the current state of } \\
\text { operations launched on particular machines on a } \\
\text { Kanban Board (cf. Sect. 4.2.1) }\end{array}$ \\
\hline $\begin{array}{l}\text { Sensor-based location } \\
\text { tracking }\end{array}$ & $\begin{array}{l}\text { Shop floor } \\
\text { worker, } \\
\text { management }\end{array}$ & $\begin{array}{l}\text { Location sensing is concerned with identifying the } \\
\text { location of manufactured parts on the shop floor. Each } \\
\text { shop floor worker is able to see, as part of the user } \\
\text { interface of their tablet, the part's location on the shop } \\
\text { floor. The location is visualized in a table with the } \\
\text { highlighted workplace the part is closest to }\end{array}$ \\
\hline
\end{tabular}

calculations. Older workers seemed to be reluctant due to their preference of paper and pencil.

\section{CEE 2: Facilitation of (real-time) production state tracking}

CEE2 comprises the aspects depicted in Table 4.4. In the following, the evaluation results with respect to the individual features are described.I

Display and autonomous selection of work tasks

This feature was already discussed to a great extent in the context of CEE 1 . The respondents' answers were mainly linked to statements on the work task reporting and change proposals. An addition was the problem of the simultaneously running system in the company that led to the perception of additional, duplicate work while using the feature.

\section{Kanban Board}

The management appreciated the feature's ease of use; the only objection in this matter was manually entering tasks into the system. This is due to the simultaneously implemented and running ERP system. Again, the comment of duplicate work arose, as the system provides similar information as displayed in the ERP system. The opportunity to manage production via digitized work support was considered an advantage. However, the system limitations became apparent in Company A, as the production manager is not permanently present at the computer to follow the tasks. This would require the use of a mobile device by management to immediately receive requests and be able to react.

\section{Sensor-based location tracking}

The introduction of a new ERP system in parallel to the case design, implementation and evaluation decreased the initially identified problem of lost parts on the shop floor by manual scanning of items. However, the location sensing has been tested. The respondents stated that it is a good idea but not necessarily required by 
small companies such as Company A. Furthermore, the duplication of tracking within two systems (new ERP system) and the processing system developed within this case were perceived to increase duplicate work. Related to the technical maturity of the sensors, the respondents noticed that the location updates take too long (sometimes up to $10 \mathrm{~min}$ ), and the precision of the part location is too coarse grain. Furthermore, they reported for practical application the limited battery lifetime of the active trackers hampering utilization, and trackers getting damaged easily when positioned especially on big parts.

CEE 3: Facilitation of production process analysis

This case evaluation element comprises mainly analysis support features. By gathering context-sensitive process data (power consumption data, location tracking, production time submitted by workers), the system enables analyzing data that could be used in the future production planning process, e.g. for more precise time estimations. This is vital for technologists and the management.

According to a technologist, recognizing the impact of this feature is not possible on short notice, given the short evaluation period in the factory. The data collected on the time spent on particular tasks or orders should be used for further price calculations. The shop floor workers entered the time, but the technologist will only be able to evaluate the usefulness over a longer period. Both, the technologist and manager see the feature's potential not only in further price estimations resulting in more precise price calculations, but also in terms of remunerating employees accordingly.

This feature was also commented on by the executive director and production manager. Both perceive the potential of the feature and its contribution to better price calculations, but need to analyze these features for a longer time period.

CEE 4: People-Centeredness

\section{The shop floor worker perspective}

The features presented in CEE 1-2 aimed to increase autonomy and involvement of shop floor workers via digitized work support. However, the interview responses indicate that workers prefer immediate face-to-face communication and fear that digitized communication takes too long and requires too many resources. Especially for their small shop floor with around 35 workers, they consider direct communication to be more effective and efficient than digital support. They are in doubt about the immediacy and added value of digital communication in their company.

Furthermore, the predominant work culture follows a hierarchical organization. Thus, workers do not really question production plans and work schedules, but rather try to implement the targets in the best possible way according to the given specifications. In addition, the time pressure could hinder active participation and involvement of workers.

\section{The management perspective}

The shop floor supervisors appreciated the opportunities for employees to be involved in the decision-making and production processes. However, the feedback 
from shop floor workers questions the willingness of workers to participate in decision-making, proposing and requesting changes. The feature testing showed a kind of reluctance and incredulity of employees towards implemented features and devices. In the case evaluation, the management was able to gain evidence that not only technological changes, such as the developed IT support, need to be carefully implemented, but also organizational changes related to the decision power and encouragement of workers to make them actively contributing to workplace improvement.

\subsubsection{Discussion of Evaluation Results}

The analysis, design and implementation activities described above were strongly people-centred and aimed to receive early feedback on solutions to direct development accordingly. Hence, one would have expected very positive feedback from the case evaluation. However, (work) reality at Company A has proven to be different. What happened? Why did the project not meet the actual expectations? This section tries to identify factors leading to the given evaluation results.

\subsubsection{Organizational Changes}

Company A experienced several organization changes within the project duration (October 2013-September 2016). Seeking for solutions to stabilize company performance, different managers were hired and alternated predominantly in 2014. The company culture was being adjusted according to the new management's directives affecting employees' positions and personal relations. Especially 2015 brought significant changes to the company's operation. The company management decided to decrease the staff (from 46 to 35 ), in order to reduce costs and provide higher salaries for the remaining employees. These changes also affected the position of the previous sales manager, Mr. Supportive, who was the main driver of the project implementation in Company A. Mr. Supportive was substantially involved in the implementation and helped to motivate workers to specify the case and propose solutions valuable for them and the project.

The layoff also pertained to three employees who participated in the case formation at the very beginning. Their valuable contributions and motivation within focus groups or internal meetings helped to frame the case implementation that finally led to opposing results in the evaluation.

Simultaneously to the significant organizational changes, the company also faced financial problems, resulting in a potential company closure. This pressure might also have led to the reluctance towards implemented project solutions. Struggling for company survival, the workers rather focused on the daily operation than on comprehensive project implementation.

\subsubsection{Technical Changes}

Aside from the addressed organizational changes, technical changes challenged the project implementation. During the implementation phase, a new ERP system was 
introduced in Company A. Interfacing this system caused delays in the project progress. Furthermore, the new ERP system covered some functionalities similar to the process support developed within this project. Thus, features have been perceived as duplicated and redundant work effort.

\subsubsection{Management Commitment}

The company changes also affected the management level. In the first two project years, three different managers were in charge with different attitudes towards the project and its implementation. In certain periods, the project was overshadowed by the company's business issues, and its objectives were put to the background. While the company owner together with Mr. Supportive drove the project, some managers perceived the project rather being vague than closely related to the concrete business model of the company. This resulted in some discrepancies in management.

The management installed during the evaluation decided to foster the project implementation, but simultaneously to focus on factory operation, as it pursued cost cutting and similar measures as part of its crisis management. Furthermore, the owner moved to the background, as his daughter became part of the new management team.

\subsubsection{Takeaways from the Case}

Company A and the regional IT consultancy project partner analyzed the project implementation and identified a list of experiences and events that have had impact on the project results. Undoubtedly, the project has created the unique opportunity for both partners to develop innovative solutions, and the project implementation will be definitely useful for different types of production companies. Selected lessons learnt are presented subsequently.

\section{Continuously discuss the project progress with relevant stakeholders}

In the course of project implementation, Company A has experienced significant changes on the management and worker level. For instance, due to the required increase of production efficiency, a crisis manager was hired. New managers seemed not always to be committed to the project objectives. Therefore, they did not support the project implementation adequately. It is advisable to discuss continuously the project course with the management and more precisely present the project impact on the current as well as on future production. The same applies to workers. In the case where the workers who were actively involved in the solution design leave the company and the workers who were not part of the design process evaluate the solution, incoherent results are very likely.

\section{Adequately involve workers}

The main project objective has been the people-centeredness. The Slovak partners have made a maximum effort to involve all relevant workers, especially shop floor workers. Although shop floor workers have been involved in the project implementation as envisioned in the project proposal, project progress was not 
adequately presented and discussed with the shop floor workers. The focus of communication was between project managers and higher management representatives at Company A and the regional IT Consultant. This may have circumvented the shop floor workers.

\section{Carefully introduce features related to aspects of "employee monitoring"}

Some of the implemented features could be considered to target "employee monitoring" (e.g. power consumption, time monitoring, etc.), although the implemented features were proposed, developed and implemented with regard to people-centeredness. The feedback related to the fear of continuous work monitoring could have had an impact on the worker resistance towards the developed solutions. The employees should to be assured continuously on implementing the solution's benefits for them. Accordingly, monitoring results should be used for triggering people-centred improvements rather than penalties (like salary cuts or negative impact on the position within the company).

Reserve sufficient time for on-site testing

Although the project set out sufficient time for testing, some of the features could not be evaluated to a representative extent - enabling to draw conclusions. Moreover, some of the features show their impact and benefits on a long-term basis. More time should have been reserved for comprehensive tests and deficiency corrections even during initial testing.

Cooperate closely with providers of existing IT systems to be interfaced

During the project implementation, Company A implemented a new information ERP system. Some system features collided with the proposed solutions and, to a certain extent, affected some of the project activities. It would have been more practical for the regional IT consultant to take part in the analytical sessions between Company A and the ERP provider enabling the alignment of redundancies and interfaces.

\section{Changing environments requires agile case specification support}

As defined in the original project plan, the use cases were defined in the first project phase at the very beginning. The total project implementation covered the period of 3 years and faced changes on different levels of the company. The changes on the management level, staff layoffs and other implemented changes, had an impact on the relevance of the originally defined case. Changing company conditions led to new requirements that have not immediately been incorporated into the solution. Therefore, an agile approach to specifying requirements and features is considered beneficial to meet industrial demands. 


\subsection{Conclusion}

This case captures the initial situation of Company A, an SME offering the production of atypical, unique and special-purpose machinery, equipment and technological complex units, particularly useful in the automotive and electronic industries. Based on the initial analysis and requirements definition results, the case represents a human-centred design approach accompanied by formative valuation activities. Within the solution development, a novel approach towards modelling S-BPM has been developed and implemented at Company A. The resulting process model also encompasses the integration with sensor technology, in order to support location tracking and power metering of machining operations.

Even though the formative evaluation informed design and implementation to provide adequate solutions for workers, significant organizational changes at Company A during the implementation question the acceptance and benefit of the developed solution as well as the goal achievement with respect to the initial situation.

However, the novel S-BPM approach to modelling the core process as well as the UI process represent major technical innovations. They have been applied for the first time within this project. Furthermore, the enrichment of S-BPM with techniques from human-centred design techniques, such as mock-up prototyping has been experienced as beneficial for aligning different solution ideas among the diverse project stakeholders (i.e. six partners from five different nations).

\section{Reference}

Kannengiesser, U., Heininger, R., Gründer T., \& Schedl, S. (2016). Modelling the process of process execution: A process model-driven approach to customising user interfaces for business process support systems. In International Workshop on Business Process Modeling, Development and Support (pp. 34-48). Springer International Publishing. doi:10.1007/978-3319-39429-9_3.

Open Access This chapter is distributed under the terms of the Creative Commons AttributionNonCommercial 4.0 International License (http://creativecommons.org/licenses/by-nc/4.0/), which permits any noncommercial use, duplication, adaptation, distribution and reproduction in any medium or format, as long as you give appropriate credit to the original author(s) and the source, provide a link to the Creative Commons license and indicate if changes were made.

The images or other third party material in this chapter are included in the work's Creative Commons license, unless indicated otherwise in the credit line; if such material is not included in the work's Creative Commons license and the respective action is not permitted by statutory regulation, users will need to obtain permission from the license holder to duplicate, adapt or reproduce the material.

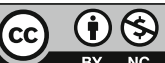

